\title{
Las ultimas cuevas. Observaciones en torno a la ocupacion historica de las cuevas astur- leonesas
}

\author{
The last caves. Precisions on historic times occupation of caves in Asturias- \\ León
}

Alfonso Fanjul Peraza *

\begin{abstract}
RESUMEN
Durante décadas, la ocupación histórica de las cuevas cantábricas, ha centrado numerosos debates, que pese al cada vez mayor número de datos, procedentes de intervenciones arqueológicas, se mantienen en pleno auge en la actualidad.

El grado de "indigenismo" de las poblaciones cantábricas al final de la romanización, el posible éxodo visigodo en las zonas de montaña, o la existencia o no, de un eremitismo cantábrico, son algunos de los temas que más han dependido, de una u otra forma, de las ocupaciones históricas en nuestros espacios subterráneos.

Partiendo de un estudio particular de cada yacimiento, las conclusiones de nuestro trabajo, demuestran la falta de conexiones con el hábitat prerromano, la dificultad para definir fenómenos de eremitismo, y apuestan, por una funcionalidad agropecuaria para la mayoría de nuestras cuevas, a modo de "cuevas-braña", que aparecen con claridad desde finales del período romano.

La falta de esa tradición prerromana, desde la óptica arqueológica, se ve suplida desde la antropología, por la extraordinaria fuerza de las creencias precristianas en torno a nuestras cuevas, resaltando el papel de la mentalidad popular, como el último baluarte cultural, de una sociedad rural en permanente transformación.
\end{abstract}

Palabras clave: Cuevas, poblamiento, eremitismo, mitología, cerámica.

\section{Objetivos y método de estudio}

Siempre analizadas desde una perspectiva puramente prehistórica, el devenir de las cavidades astur-leonesas en época histórica hasta nuestros días ha sido un tema totalmente marginal en la investigación arqueológica.

\begin{abstract}
During decades the historical occupation of the Cantabrian caves has been in numerous debates. In spite of all the information taken from archaeological interventions the debate is still alive.

Some of the topics that are strongly related to this debate are for example the degree of pre-roman tradition of the Cantabrian populations at the end of the roman times, the possible Visigoth exodus in the mountain areas and the possible existence of Cantabrian eremitism.

The individual study of every cave firstly demonstrates the lack of connections with the pre-roman settlements in caves, then the difficulty to define phenomena of eremitism and finally we support the idea of a rural functionality of the most part of the archeological sites. This kind of settlement appears with clarity at the end of the Roman period.

The lack of this pre-roman tradition is replaced by the extraordinary force of the pre-Christian beliefs. This situation shows the value of the popular mentality in a rural society in permanent transformation.
\end{abstract}

Keywords: Caves, settlement, eremitism, mithology, pottery.

Pese a lo simple del registro analizado y la escasez de materiales localizados, las variables interpretativas son muy numerosas y la propia escasez de estudios previos confiere complejidad a un tema en el que nos podemos encontrar desde ocupaciones pastoriles, rituales, industriales, pasando por ocupaciones domés- 
ticas puntuales, que pueden ser interpretadas como el resultado de la huida o escondite, de algunos grupos humanos, en determinados momentos de la convulsa historia cantábrica.

Nuestro trabajo ha partido de la revisión individualizada de la totalidad de las sesenta y nueve cuevas con ocupaciones romanas y medievales de Asturias y León (Figura I), entendiendo que, desde el punto de vista cultural e histórico, las analogías geográficas nos permiten establecer una única región de estudio diferenciada, en lo que al tema nos refiere, del cantábrico oriental, donde las ocupaciones rupestres son muchísimo más numerosas.

Este análisis pormenorizado de los yacimientos, pese a los grandes problemas del registro localizado en las cuevas estudiadas y su posterior interpretación, nos ha permitido, en primer lugar, establecer un mapa regional actualizado para este tipo de poblamiento, y posteriormente, abordar de forma monográfica el porqué de estas ocupaciones, lejos de los breves análisis generales que se habían hecho hasta el momento, partiendo siempre de la base de algún yacimiento en concreto.

Este trabajo dispone por lo tanto de varios modelos de análisis, uno documental; otro de campo, destinado a la revisión de los yacimientos y sus datos conocidos, y otro puramente teórico e interpretativo, donde nos hemos dedicado a buscar las razones y los paralelismos de las ocupaciones en cueva, tanto para el mundo romano como para la etapa medieval.

Desde el primer momento, partimos de una documentación basada en los inventarios arqueológicos comarcales, como primera fuente para el estudio del paisaje arqueológico que nos interesa estudiar.

Pese a que la base documental se supone fiable en la mayor parte de los casos, no faltan casos de yacimientos mal situados, o encuadrados cronológicamente en contextos que nosotros discutimos.

Este tipo de problemas no afectarían mucho al estudio si no estuviésemos, a día de hoy, ante la existencia de amplias zonas que requieren una prospección intensiva, por el alto riesgo de hallazgos de yacimientos en cueva, y que de momento no se ha producido.

Un buen ejemplo de esta situación la tenemos en León, donde pese a las recientes revisiones de los inventarios comarcales, todavía a comienzos de los años noventa se hablaba de zonas aun inexploradas, como el sector atribuido a la antigua cultura Vadiniense, calificado en su día como de "conocimiento arqueológico casi nulo" (MAÑANES 1990, 163).

Estamos, por lo tanto, hablando de un territorio cuya exploración es incompleta y la mayor parte de los datos son producto de una labor de prospección escasamente revisada en los últimos treinta años. No son de extrañar, por lo tanto, las extremas dificultades para localizar algunos yacimientos, la total falta de datos materiales en el $90 \%$ de los mismos, o incluso la total desaparición de algunas de las cuevas que pretendíamos revisar, como la Ferrería en Las Regueras y Serrapio en Aller (Asturias).

Desde la perspectiva historiográfica, la casi absoluta focalización de las investigaciones en momentos de ocupación paleolítica ha provocado que muchas de las referencias a posibles ocupaciones históricas sean absolutamente indirectas, basadas en alguna observación o apunte en diarios de excavación o en memorias publicadas parcialmente, donde se cita la existencia de "cerámicas negras", sin especificar ni cronologías, ni posibles hipótesis de contexto arqueológico.

El registro material es por ello escaso, descontextualizado en la mayor parte de los yacimientos, o simplemente forma parte de referencias documentales, cuya base puede ser en algunos casos discutida.

Tal situación es la que nos lleva, pese a la escasez de material, a adscripciones generales de uso cronológico, sin tener en cuenta el número de objetos de esa época hallados en el lugar, ya que en la mayoría de los yacimientos esos fragmentos cerámicos, monedas u otros elementos, no superan la decena de materiales (Figura 2). 
Siguiendo con la problemática material, hemos de resaltar la confusión en la asignación crono-cultural de las producciones cerámicas que se denominan comunes, sobre todo en aquellas que, realizadas a mano, parecen tener una cronología bien protohistórica o bien corresponden a producciones históricas entre la tardorromanidad y el Altomedievo.

La solución, en estos casos, pasa por realizar un intento de adecuar geográficamente el contexto de la cueva con las pautas de diferentes épocas, y si bien existen yacimientos que, aun así, permanecen sin poder ser contextualizados en base a la simplicidad de su principal hallazgo material, otros nos dan claves de ubicación que nada tienen que ver con los prototipos de yacimientos protohistóricos. En estos yacimientos la asociación de cerámicas a mano a lotes medievales o romanos, sí nos está indicando posibles ocupaciones tardías de época altomedieval.

De la misma forma, los problemas de identificación cronológica para la cerámica medieval de la región en estudio son realmente importantes, con unos modelos, decoraciones y tipos de cocción que han convivido durante siglos, lo que nos exige a encuadrar los hallazgos en grandes etapas cronológicas, para evitar errores mayores.

\section{El problema de las cerámicas a mano altomedievales}

Hasta nuestros días, y de forma repetitiva, la aparición de cerámicas a mano en un yacimiento en cueva hacía suponer a los investigadores, que estaban ante una indudable ocupación prehistórica.

Nuestra revisión de yacimientos chocaba con muchas de las asignaciones cronológicas, destacando una extraña relación entre cuevas tardorromanas y medievales, claramente datadas y ajenas a las pautas de ubicación de la mayoría de las cuevas de la protohistoria, con el hallazgo de cerámicas a mano.

Esta situación nos lleva a plantear un esquema de producción de cerámicas a mano en época altomedieval, que si bien son claramente detectables en la meseta norte, aparecen de forma más confusa y menos estudiadas en la costa cantábrica (figura 3).

Los problemas de definición tienen como base unas clasificaciones complejas en muchos casos, por la calidad del registro, sobre todo en lo que se refiere a las producciones manuales y las realizadas en cocciones muy precarias. En muchos casos, estas producciones de baja calidad, con gruesos desgrasantes y paredes irregulares, "acostumbra a generar equívocos con la cerámica no torneada" (AZCÁRATE y SOLAUN 2008, 140).

Estas confusiones no son propias, como es de imaginar, únicamente de nuestro marco de estudio, y así, en el País Vasco (BARANDIARÁN 1946, 27) se han definido como Neo-Eneolíticos niveles de ocupación tardoantiguos, caso de Peña Forua (MARTíNEZ y UNZUETA 1988, 9). En otras áreas de la Península Ibérica las diferencias entre producciones cerámicas romanas, medievales e islámicas son tan evidentes en la zona que, por exclusión, los yacimientos históricos de cerámicas manuales han quedado clasificados como lugares de ocupación hispano-visigoda entre los siglos $V$ y VIII d. C. (LALIENA y ORTEGA 2005, 77).

Desde el punto de vista técnico, estamos mayoritariamente ante modelos de ollas, platos gruesos y tinajas de almacenamiento de cereal, realizadas con una mala calidad de cocción a través de hornos muy artesanales o temporales, desgrasantes gruesos, a los que se añaden, elementos de menor tamaño como la mica y donde la única solución estilística pasa por un espatulado o leve bruñido, según el tamaño de las piezas y su función.

Desde el punto de vista social, estamos ante producciones puramente rurales y autosuficientes, que cubren de forma barata buena parte de una vajilla familiar, que no tiene acceso a producciones importadas o de calidad.

Desde el punto de vista cronológico, surgen en la vajilla Bajoimperial a partir del siglo III d. C., en paralelo a la intensificación del poblamiento rural autosuficiente, aumentando su presencia en paralelo al descenso de las importaciones. 
El final de las mismas, entre los siglos $\mathrm{VI}$ y $\mathrm{VII}$ d. C., marca el punto álgido de las producciones a mano en la costa cantábrica (AZCÁRATE y SOLAUN 2008, 140) y la meseta norte, manteniéndose en Asturias tan sólo hasta el siglo VIII d. C. si tenemos en cuenta la secuencia de Curiel (GUTIÉRREZ GONZÁLEZ y RODRÍGUEZ VÁZQUEZ 2003, 20I), al igual que en la vecina Cantabria (BOHIGAS y RUIZ 1989, 31).

En el cantábrico occidental, caso de Galicia, perduran hasta el siglo siguiente (IX d. C.) (SUÁREZ, GIMENO y FARIÑA 1989, 287) y su tradición técnica sigue dejando huella en la tosquedad de ciertas producciones altomedievales cantábricas hasta el siglo $X$ d. C. (SOLAUN BUSTINZA 2005, 366).

Estamos, por lo tanto, ante producciones, que, si bien abarcan desde siglo $\mathrm{V}$ al VIII d. C., en la mayoría de los casos se quedan seguramente en el VII, sobre todo en aquellos sectores más próximos a centros de intercambio comercial o de cierta entidad poblacional. En el siguiente siglo final, el VIII, no aparecen en Cantabria, quedando como reducto tecnológico, la mala calidad de pastas, desgrasantes y cocción, algo que también se observa de forma masiva en las producciones asturianas periurbanas, como las de Faro, donde en su testar más antiguo (SUÁREZ SARO 1980) se fechan las producciones de peor calidad en el siglo $X$ d. C y que, según nuestra opinión, en base a los paralelismos cantábricos, puede retrotraerse hasta el siglo VIII-IX d. C.

La presencia de estas piezas a mano en cuevas, junto a producciones claramente tardorromanas (Cueva de Chapipi) y en otros casos altomedievales, hace que podamos hablar de una potente ocupación de las cuevas asturleonesas en época visigoda, detectándose una intensiva ocupación en los valles de montaña (figura 4), donde son predominantes (El Greyu, Copilae, Laspru, Prendada, Calluanga, Orpiñas, Cudrera, Prida, Buseco, El Fontanón II y El Fontanón III), y posiblemente también en espacios de gran calidad agrícola como las vegas del río Nalón y el Narcea (Cueva Grande en Salas) (Figura 5), donde el contexto protohistórico de algunos yacimientos, donde aparecen estas producciones, debe ser en nuestra opinión discutido.

\section{Entre eremitas, campesinos $y$ refugiados}

La arqueología de las cuevas no ha permanecido al margen de los problemas que, en general, ha sufrido la arqueología romana y medieval en España en los dos últimos siglos. Esta situación se debe a que en nuestro contexto de estudio son muy numerosos los temas a tratar, bien en el contexto de la cultura material, el poblamiento, o en el ámbito de las ideas y la religiosidad.

La ocupación de las cuevas en época histórica ha sido interpretada desde diferente enfoques, en lo que al norte de España se refiere. Desde comienzos del siglo $X X$ y en plena edad del oro de la arqueología subterránea cantábrica, los primeros trabajos respecto a nuestro tema de estudio apostaron por tres líneas de trabajo, que de forma repetitiva y con escasas variantes se presentarán a lo largo de la investigación arqueológica hasta nuestros días.

Por un lado, encontramos la hipótesis del "éxodo visigodo", ya presente en los trabajos de L. Barrau-Dihigo (1919 y 1921), que defiende un origen visigodo de las ocupaciones medievales de nuestras cuevas, en base a la emigración de las élites políticas y religiosas de la corte de Toledo, debido a la invasión musulmana.

Por otro lado, podemos definir otra hipótesis, que denominaremos "de refugio", como explicación a todos los restos tardoantiguos en cuevas, provenientes, según esta hipótesis, de unas ocupaciones puntuales, debido a la inestabilidad social de los últimos siglos del período romano.

Finalmente, hay una perspectiva "cultual", que no sólo ha tratado de definir los hábitats rupestres como eremitorios, sino que se extiende a los lugares con enterramientos romanos, bajo la perspectiva de una supuesta tradición prerromana de enterramientos en cuevas. 
Estas tres líneas de trabajo han sido hasta nuestros días, alternándose o combinándose según el yacimiento que se tratase, las que nuestra historiografía ha empleado como vías de interpretación.

A mediados de los años sesenta la identificación entre cuevas artificiales y eremitorios, es la corriente dominante en la historiografía española (PUERTASTRICAS 1965,419) si bien, una década más tarde, asistimos a un análisis más complejo del fenómeno y se comienza a sustentar la idea de un fenómeno de cuevas excavadas en la roca procedentes de un contexto puramente doméstico, anterior a lo que serán los eremitorios "de repoblación" medievales.

A finales de la década siguiente existe un cierto repunte de las posturas "indigenistas" a través de las obras de Barbero y Vigil (1978), donde se defiende el papel de los grupos locales, de raíz prerromana, en los cambios sociales, entre la tardoantiguedad y la Alta Edad Media. Esta postura, que se repite durante la década de los ochenta, tendrá su repercusión en lo referente a la ocupación de hábitats rupestres: “...de una población marginal, en pequeños poblados e incluso en cuevas,...hace pensar en la perduración de un hábitat tradicional que se mantiene siempre en la montaña, debido al fuerte arraigo de las estructuras sociales autóctonas, contra las que chocaron siempre las invasiones romanas, visigodas y musulmanas" (GUTIÉRREZ 1985, 247), resultando una paradoja historiográfica insostenible, muy bien descrita en su crítica de conjunto por Hierro Gárate (2002, 123):

"...Se nos ofrece pues, para las décadas siguientes a la invasión, una estampa cuando menos Ilamativa: nobles y eclesiasticos hispanovisigodos habitando las cavernas de un país hostil y desconocido para ellos, plagado, por supuesto, de enemigos seculares y acérrimos. Enemigos que al poco tiempo y sin que se expliquen de manera convincente las causas de tan extraño y repentino cambio, se convierten en amigos y aliados frente a una supuesta amenaza común".

Los años ochenta constituyen, dentro de un auge en cantidad y calidad de los estudios de arqueología en España, sobre todo referentes a la época medieval, una época en la que se aplican las viejas hipótesis tradicionales a los nuevos datos extraídos de las recientes investigaciones.

A partir de los años noventa el debate incorpora, cada vez más, elementos económicos y geográficos en el contexto del análisis de los pueblos altomedievales y su formación, dejando de lado viejas líneas de discusión, caso del feudalismo.

En paralelo, muchos autores en esta década no aceptan todavía la existencia de hábitats en aldea en la meseta norte hasta bien entrada la Alta Edad Media (ESTEPA DíEZ 1998, 278), o bien defienden la existencia de unos modelos sociales del poblamiento donde el viejo sistema de castros se habría revitalizado en esta época oscura. Esta línea toma como segura la existencia de sistemas sociales comunales, de origen castreño, más vinculados a la ganadería y cuya evolución social la constituye una aristocracia que sustituye al estado (MARTÍN VISO 2000, 36I).

Los últimos trabajos (QUIRÓS y ALONSO 2008, y QUIRÓS y BENGOETXEA 2006) siguen una línea más vinculada a los procesos de ocupación rural, en consonancia con nuestras hipótesis para el cantábrico central, que al hecho puntual de los refugios en tiempos de crisis, que tanto se han defendido anteriormente.

Para el caso asturiano, los hallazgos puntuales, como el de una moneda de Trajano en la cueva del Eremitán en Llagú (Oviedo) (BERROCAL-RANGEL, MARTÍNEZ y RUIZ 2002), también han sido puestos en el contexto de lo que podríamos llamar la hipótesis "multifuncional", defendida por Maya en el caso de las cuevas cercanas a yacimientos castreños. Siguiendo esta hipótesis, el uso de estas cavidades habría servido como "lugar de refugio en tiempos inseguros como los bajoimperiales, asentamientos eremíticos durante los primeros tiempos cristianos y siempre cobijo de vagabundos y pequeños grupos familiares más o menos erráticos" (MAyA 1989, 84).

Si bien la interpretación multifuncional, en este momento de la investigación, se ha mos- 
trado como la más acertada, pesa todavía la vieja hipótesis "invasionista”, referida ésta a las invasiones germánicas como explicación de los hallazgos monetarios tardoantiguos en cuevas, una línea de interpretación básica, creada en torno al concepto de "inseguridad social" que, de forma simplista, se ha seguido durante décadas en nuestra historiografía, caso de la interpretación del tesoro de la cueva de Chapipi en Grado (ESCORTELL 1975).

Esta cita es cuando menos paradigmática, no sólo por la falta de correlación con otras ocultaciones en cuevas del cantábrico, sino por hacer una extensa relación de hechos históricos que, en opinión de la autora, refuerzan la teoría invasionista como explicación de los hallazgos de Chapipi.

La relación de hechos pasa desde unas hordas bárbaras que cruzan el Rhin hasta todo un elenco de noticias peninsulares sobre la presencia de Vándalos, Suevos y Alanos, que habrían producido una inquietud, producto de "una anormalidad política y militar, que pudo ser el motivo de la ocultación del tesorillo de Chapipi" (ESCORTELL 1975, 49).

Sin duda, estamos ante una explicación continuadora de otras que, desde la arqueología del siglo XIX, han interpretado estos hallazgos monetarios y que sería comprensible en un entorno urbano afectado de forma directa por tales sucesos, pero que resulta incomprensible, según nuestra opinión, en un entorno de alta montaña, donde además se han producido otras ocultaciones importantes en los aledaños, también en lugares de un cierto contenido simbólico, caso del tesorillo de Foxó en Yermes y Tameza, lo que demuestra la fuerza económica de las comunidades de montaña tardoantiguas en determinadas zonas de la montaña asturleonesa y la posible existencia de un contexto votivo.

\section{4. ¿Tradición o innovación? la base protohistórica}

En nuestro estudio hemos contabilizado un total de cincuenta y cuatro cuevas con restos protohistóricos más o menos fiables, que en conjunto nos pueden aportar una visión general sobre el contexto geográfico de estos emplazamientos, aparte de algunas claves de tipo cultural de diversa índole que en muchos casos comparten con otras funciones, siguiendo un típico binomio hábitat-enterramiento.

A modo de observación introductoria, hemos de destacar la localización y exploración de varios emplazamientos que hasta el momento se daban como perdidos, caso de la cueva de Pueblo Bajo de Lledías en Llanes, la Fontana de Piloña, así como la identificación de un panel de arte rupestre de posible origen protohistórico, bajo otro más moderno, en Xinxanganas, Llanes (Figura 6).

El contexto crono-cultural y económico de los grupos protohistóricos del noroeste sigue bajo un constante debate, donde las dificultades interpretativas se basan en unos datos muchas veces confusos, así como en unos contextos materiales problemáticos (FÁBREGAS VALCARCE 1995, 105), más procedentes de hallazgos cultuales o funerarios que de ambientes domésticos, que nos aclaren cómo es la vida cotidiana de estos grupos (FERNÁNDEZ MANZANO y ARIAS CABAL 1999,7).

En este sentido, nos encontramos con unas producciones materiales locales de las que se pueden extraer únicamente ciertas influencias técnicas y decorativas comunes, tanto para el norte de la meseta como para el ámbito cantábrico (TOLEDO CAÑAMERO 1999, 19).

De momento, pese a los numerosos indicios que prueban la existencia de enterramientos en cueva desde el neolítico, el estado de los yacimientos y de su documentación recuperada hace que muchos investigadores sean reacios a hablar de una cultura de enterramientos colectivos (ARIAS CABAL, 1991, 225), o incluso de cuevas estrictamente rituales, si tenemos en cuenta la imposibilidad de demostrarlo a partir de los restos revueltos, en la mayoría de los casos, de elementos funerarios y habitacionales.

Una de las conclusiones a tener en cuenta es la excepcionalidad de los registros arqueoló- 
gicos subterráneos correspondientes a la Edad del Hierro. Los casos conocidos en Asturias y León nos están hablando, en primer lugar, de un tipo de cuevas periurbanas de uso desconocido, como es el caso de la cueva del hueso de Pillarno, situada bajo un poblado fortificado que posiblemente sea coetáneo en cronología.

Por otro lado, tenemos dos casos con usos funerarios, la Caronda en Piloña, que podemos definir más bien como una cista artificial excavada en la roca, así como la cueva de Pueblo Bajo de Lledías en Llanes, donde el posible uso de una urna de incineración, acompañada de varios elementos a modo de ajuar, nos traslada a unos rituales que culturalmente, de momento, son ajenos al territorio de la Asturias histórica, y que más bien habría que encuadrar en el contexto de hallazgos tardoromanos o altomedievales.

Podemos hablar, dentro de los escasos hallazgos, de una total diversidad de situaciones, entre la que estaría la convivencia de formas funerarias o votivas diferentes, como es la presencia de una posible urna cineraria y de un enterramiento en gruta artificial a modo de cista, dentro de la inexistencia de una tradición cultural, respecto a los usos previos, propios de la Edad del Bronce, donde las cavidades disponen de un uso funerario o votivo de mayor importancia, si comparamos el número de elementos descubiertos en una y otra época.

Esa inexistencia de tradición cultural, ese auténtico lapsus de usos funerarios durante casi mil años, hace que debamos interpretar las necrópolis en gruta astur-romanas como una auténtica novedad y no como tradición cultural autóctona.

\section{Las cuevas-braña y su origen astur-romano}

A través de la historiografía reciente, el pastoreo y la ganadería estacional han sido uno de los contextos más utilizados para encajar el uso estacional de algunas cuevas cantábricas. En casi todos los casos, se resalta esa estacionalidad de las ocupaciones, en base al escaso registro arqueológico que se observa en los yacimientos:

“...el uso esporádico como hábitat ocasional de las cuevas es muy frecuente en la época medieval y posiblemente hay que ponerlo en relación con las labores de poblaciones flotantes, como pastores o madereros..." (SERNA, VALLE y MORLOTE 1992, 106).

Es evidente que las poblaciones ganaderas siempre han explotado y habitado los altos valles de la montaña cantábrica desde la prehistoria. Lo que se ha puesto en debate, más que esa evidencia, es la existencia de un auténtico poblamiento de montaña, vinculado mayoritariamente a la ganadería intensiva y a los movimientos temporales de una población tradicional, equivocadamente definida como "marginal".

A partir de la época romana, los testimonios epigráficos, que nos relatan la existencia de auténticos grupos gentilicios, como los vadinienses, funcionando a uno y otro lado de la cordillera, dejan claro la existencia de esa población de alta montaña (GONZÁLEZ RODRÍGUEZ 1997, 129).

En nuestro estudio, habiendo detectado un mayoritario uso ganadero de las cuevas analizadas, desde la época tardorromana, hemos decidido acuñar el término cueva-braña para referirnos a espacios con ocupaciones domésticas no muy intensivas, dentro de entornos inmediatos, de usos económicos mayoritariamente ganaderos.

La braña constituye el elemento básico de los paisajes ganaderos de alta montaña. Si bien se identifican por sus construcciones, a modo de corros de piedra, o edificios de planta baja a modo de cuadra-vivienda con cubierta vegetal, estas construcciones son la representación física, a través de su arquitectura, de un modelo de vida basado en la explotación ganadera del paisaje, de forma estacional, disponiendo de diversos asentamientos para el hábitat, a diferente altura, según la época del año, y que podemos trasladar como espacios domésticos, también a las cuevas (figura 7). 
El origen de las brañas, a día de hoy, se explica bajo la perspectiva de tres puntos de vista. El primero alude a una población permanente que, siguiendo una tradición ganadera local de raíces prerromanas, continúa con un uso de los pastos en verano al que, con el tiempo, va incorporando estructuras de cierta habitabilidad.

La segunda hipótesis defiende la existencia de un proceso de colonización de las zonas periféricas, sobre todo a partir de la alta Edad Media, que se vería impulsado entre los siglos XI y XIII por una auténtica política de administración y expansión económica por parte de los poderes locales (figura 8).

Una tercera vía apuesta, dentro de esa génesis del fenómeno en tiempos medievales,, por un proceso de creación de las brañas bien debido a la huida de las imposiciones fiscales y al control señorial (VALLADARES ALVAREZ 2005, 69) o bien debido a las ordenanzas de uso y explotación de puertos de montaña, que favorecen, sin necesidad de huir del poder local,, una vida de los grupos locales mucho más relajada a nivel fiscal que en otros sectores de la montaña asturleonesa.

Ante estas tres líneas de trabajo tradicionales, se impone desde la perspectiva arqueológica una vía menos "rupturista" y que plantea la continuidad habitacional del poblamiento altomedieval en los altos valles (BOHIGAS ROLDÁN 1999, 368), dentro de un contexto geográfico totalmente dinámico, desde siglos anteriores, en lo que respecta a su explotación y organización territorial (PEREZ RODRÍGUEZ 1999, 349).

La importante presencia de cuevas-braña tardorromanas que planteamos para la montaña asturleonesa (El Greyu, Copilae, Laspru, Prendada, Calluanga, Orpiñas, Cudrera, La Prida, Buseco, El Fontanón II y El Fontanón III) creemos que va en paralelo a la propia génesis de la aldea tal y como la conocemos hoy en día (QUIRÓS CASTILLO y BENGOETXEA, 2006 y QUIRÓS CASTILLO 2006).

El declive final de las villas y haciendas rurales romanas a partir de los siglos $\mathrm{V}$ y $\mathrm{VI} d$. C. supone la multiplicación de los asentamientos de aldea, con un aumento tanto de la producción agrícola como de la explotación ganadera (VIGIL ESCALERA 2007, 275). Este modelo, bien constatado en la meseta y el valle del Ebro, parece advertirse también en el noroeste, si tenemos en cuenta reocupaciones, a modo de aldeas tardorromanas, de viejos castros como la Garba de Berrueño (FANJUL PERAZA y otros 2007).

La falta de una arqueología de los "despoblados" en la zona en estudio es la culpable de que las fechas admitidas mayoritariamente para el origen de este fenómeno, en nuestro ámbito de estudio, sean más tardías (RODRÍGUEZ RESINO 2008, 219).

Esta regresión material y de las estructuras de hábitat no puede calificarse, en nuestra opinión, de "tradición protohistórica" como apuestan algunos investigadores (VIGIL-ESCALERA 2000), ante lo que consideramos una clara falta de continuidad desde la Edad del Hierro hasta las aldeas altomedievales.

Los hallazgos de cerámica medieval en Cuacuartel y Trillacueva demuestran la existencia de brañas en tiempos tempranos de la Edad Media. Incluso si conseguimos demostrar la tardoantigüedad de algunos fragmentos de cerámica a mano que aparecen también en estos registros, podríamos concretar un momento inicial bien documentado entre los siglos $V$ y VIII, en las que ya se establecerían un conjunto de puntos de poblamiento, seguramente estivales, cuya continuidad queda demostrada con la presencia de cerámicas medievales, tanto en esos mismo lugares como en cuevas de entornos geográficos similares (El Collau, Laspru, Barbaroña, Cueva Cabrera, El Fontanón II, Cuacuartel, Chinariega B, Chinariega A, La Salona, Castro Blanco, Les Beleñes, Les Xanes, El Arroyo, Covachos de Canseco, Sanchuzano de Gerás, San Mateo, y Abrigos de Corona).

En cuanto al modelos de vida de estos grupos, lo que parece demostrarse a través de los registros arqueológicos documentados hasta el momento (Figura 9) es que no estamos ante 
gentes que realizan su vida de forma totalmente autosuficiente, si tenemos en cuenta el repertorio de piezas de clara vinculación comercial, que aparecen en algunas cuevas asturleonesas y cántabras, caso de la Garma (BOHIGAS y RUÍZ 1989, I10).

Por otro lado, muchas de las actividades de ocupación se restringen a las zonas donde existe mayor cantidad de luz natural, es decir, la entrada y el exterior de la cueva, lejos de posibles espacios internos que podrían dar pie a interpretaciones de tipo cultual o ritual.

En este sentido, las descripciones etnográficas de las cavidades-braña de los Picos de Europa (BALLESTEROS 2002 y VALLADARES ALVAREZ 2005, 42), nos muestran un modelo simple, con muro exterior, separación interior mediante entretejido de ramas, y un fuego próximo a la entrada.

En casos más complejos, como el de la cueva Armada, en el desfiladero del Cares, se nos relata la existencia de una cueva que no sólo aprovecha el abrigo para la creación de dos plantas de habitación y cuadra, sino que además, aprovechando las galerías interiores, dispone de cocina, despensa, almacén, leñera y gallinero (GARCÍA FERNÁNDEZ 1962).

Es evidente, por lo tanto, no sólo un uso intensivo como brañas de estos espacios en cueva (figura 10) desde la tardoantigüedad, sino también una complejidad estructural, demostrada desde la etnografía, de la que no quedan huellas en los registros arqueológicos actuales.

\section{Las cuevas sagradas. De las necró- polis astur-romanas al supuesto ere- mitismo cantábrico}

Los depósitos revueltos, los cuales constituyen más del noventa por ciento de los estratos de época histórica estudiados en el norte de España, apenas nos resultan útiles a nivel interpretativo, más allá de aportar nuevos materiales y un nuevo emplazamiento en el mapa.
Esta situación supone una problemática añadida a la identificación de yacimientos, para los que en muchos casos apenas contamos con elementos materiales que los definan culturalmente.

La única solución proviene de una exhaustiva y buena documentación de los registros arqueológicos, sobre todo en lo que se refiere a las secuencias estratigráficas de cada yacimiento, así como de interpretar cada yacimiento en su contexto (AZKÁRATE 1988,478), lejos de generalizaciones para el fenómeno.

A grandes rasgos, y dentro de la complejidad particular de cada yacimiento, así como de los problemas generales de identificación ritual que se dan para esta época (ABASOLO y PÉREZ 1995, 293), Contamos con usos rituales de época astur-romana y altomedieval (figura |I).

Siguiendo este esquema, que ya estableció en su día de forma similar P. Palol (1954), es fácil hallar una convivencia entre los elementos materiales que identifican culturalmente alguno de estos registros funerarios, caso del enterramiento altomedieval de Fresnedo en Asturias.

De la misma forma, y dentro de las influencias culturales y materiales que en esa época están adquiriendo las poblaciones locales, es también frecuente observar elementos foráneos, propios del ritual gótico, dentro de los enterramientos hispano-visigodos, lo que resalta aún más su carácter pagano (SERNA, VALLE y HIERRO 2005).

Las altas cronologías de los ritos funerarios hispano-visigodos en cueva, datados recientemente en el siglo VII-VIII d. C., han supuesto el retorno a un viejo debate sobre la pertenencia o no de estas poblaciones de montaña a un reino visigodo, donde el cristianismo es la religión oficial desde hace tiempo.

Desde el punto de vista historiográfico, ha tenido un gran peso el contexto "etnicocultural" en lo que a interpretaciones se refiere, frente a un análisis puramente arqueológico del material y su adscripción cronológica (MENÉNDEZ BUEYES 200 I y 2006). 
Independientemente de su pertenencia cultural y religiosa, los más recientes estudios de síntesis sobre esta problemática, basados en el análisis de cuevas de época histórica en Cantabria (HIERRO 2002 y SERNA, VALLE y HIERRO 2006), así como en el arco atlántico europeo (BRANIGAN Y DEARNE 1992, 19, BRANWELL y otros 1983, BRANIGAN y BAYLEY 1989, 48-49), demuestran que siempre hay un factor de relación con los centros de población, concentrándose muchos de los enterramientos en las cercanías de zonas intensamente pobladas en algunos casos, mientras que en otros como las cristiano-visigodas, parecen estar vinculadas a los valles de alta montaña.

Esta vinculación geográfico-cultural nos hace plantearnos la posible existencia de unas primeras comunidades religiosas, dedicadas a la cristianización de las poblaciones más periféricas.

Otra vía de interpretación, hasta ahora la más repetida, se ha basado en lo que llamaremos la hipótesis "invasionista", que explicaría el hallazgo, en cuevas y valles periféricos de montaña, de elementos de gran calidad material propios de áreas de cierta importancia socioeconómica.

Si bien esta hipótesis la encontramos también en el caso de las tesaurizaciones, lo cierto es que se ha basado sobre todo en los restos funerarios pertenecientes a los grupos cristiano-visigodos. El fósil director de los mismos, los jarros litúrgicos, ha sido objeto de debate durante el último siglo, siendo la principal base teórica que, para los seguidores de esa hipótesis invasionista, demostraría el desplazamiento visigodo hacia las montañas cantábricas con motivo de la invasión musulmana.

En este sentido, son demasiadas las dudas que con los años ofrece esta teoría, que nosotros discutimos. Por un lado, el lugar de los hallazgos cantábricos parece restringirse a comunidades de montaña, lo que estaría más en consonancia con la hipótesis de una política de cristianización, mientras que, por otro lado, parece ya demostrado a través de las últimas revisiones materiales (AVELLO 1985-1986) que nos encontramos ante productos realizados por un taller regional, lo que indicaría la inexistencia de un "traslado" material y también poblacional desde Toledo, con motivo de la invasión.

Finalmente, nos encontramos con dudas en la asignación cronológica de estos materiales, debido a la total descontextualización de los hallazgos que actualmente conocemos.

Estas dudas creemos que son suficientes para rechazar la hipótesis invasionista y apostar por la existencia de unas comunidades que, bien por motivos propios, vinculados a unos centros religiosos, o bien producto de una política estatal de cristianización de la alta montaña cantábrica, están presentes entre los siglos VII y VIII d. C. en nuestra zona de estudio.

En este sentido, los recientes estudios sobre cuevas tardoantiguas y altomedievales de Cantabria (HIERRO GARATE 2002, 124) rechazan de plano la hipótesis invasionista como explicación del uso de las cuevas Cántabras durante este periodo, basándose, sobre todo, en que el incremento del uso de las cuevas tardías de Cantabria comienza a desarrollarse durante el siglo V d. C., con un incremento en el siglo VII d. C., es decir, un período anterior a la invasión musulmana.

En líneas generales, parece que estamos ante cuevas de difícil acceso, donde incluso se observan muros o estructuras que protegen el espacio funerario interior, formado por galerías muy estrechas, que llevan a uno o dos niveles de diferente profundidad y que en ocasiones, comparten su registro, con lo que parecen ocupaciones previas.

Las dificultades de acceso, son un factor común de las cuevas funerarias tanto de época prerromana, como de los tiempos históricos, con lo que el hallazgo de materiales de ambas épocas, debe observarse como una coincidencia geo-funcional, y no como un rasgo de tradición local.

En cuanto al repertorio de hallazgos materiales, el conjunto es repetitivo, con materiales de vidrio, cerámica, elementos de adorno 
personal, armas, herramientas, monedas y una amplia variedad de restos de animales, que demuestran tanto las vinculaciones económicas del grupo, como determinados ritos posiblemente funerarios, cargados todavía de un fuerte paganismo, caso de los sacrificios de caballos o gallos, junto a los cadáveres.

Respecto a los restos humanos, suelen mostrar a una población joven, sin restos infantiles ni de ancianos, y con una población femenina importante a nivel estadístico.

Los materiales de trabajo, siguen apareciendo de forma abundante durante el siglo $\mathrm{V}$ d. C. y han sido interpretados bien como una indicación del trabajo que realizaba el difunto, o bien, elementos simbólicos, propios del ritual tardorromano, cuya adscripción religiosa, nos es hasta el momento desconocida.

Su hallazgo es generalizado en las necrópolis del valle del Duero, así como en el sur de la meseta y extremadura (FIGUEROLA 1984-1985, 373), y su presencia en nuestra zona de estudio se circunscribe a la Feliciana en León, con un posible carácter funerario, y a la cueva del Ferrán, en Asturias, donde posiblemente estemos ante un lugar de usos votivos y funerarios, si nos atenemos a las referencias de la documentación hoy perdida (Figura 12).

Respecto a la existencia de fenómenos de eremitismo en el cantábrico central, tanto la vinculación de los hallazgos de Fresnedo, con el vecino y posterior centro religioso de Presorias (FERNÁNDEZ MIER y FERNÁNDEZ HEVIA 1998, 106), así como el de otros elementos litúrgicos en cueva, no nos permiten demostrar dicha relación en el plano arqueológico y se mantienen a día de hoy como una suposición. La cueva, habría actuado en este caso como un lugar de enterramiento puntual, donde la comunidad que hace uso de ese espacio, parece residir al aire libre en sus inmediaciones, y no nos permite definir a un grupo de eremitas.

Los únicos casos claros de nuestro área de estudio, donde más allá de fenómenos de eremitismo, podemos hablar de usos religiosos, son algunas de las cuevas excavadas en roca del valle del Esla. El sentido periurbano de las mismas sigue siendo muy fuerte, $y$ las inscripciones fundacionales que hemos estudiado en algunas de esas cuevas, caso de cueva los Moros de Mansilla (Figura 13), nos llevan a momentos avanzados de la Edad Media, con lo que de momento, no podemos vincular por completo ese sentido religioso, con una actividad eremita en un sentido estricto del termino. Otros lugares como la cueva de San Martín, a las afueras de León, parecen responder, si tenemos en cuenta su ubicación y entorno inmediato, a espacios de culto vinculados a lugares de cierto simbolismo, más allá de constituir estructuras de poblamiento humano.

\section{Otras ocupaciones particulares. Los usos periurbanos y los escondites}

Existen varios modelos de cavidad, cuya ubicación y restos encontrados, nos permiten catalogarlas en una función muy determinada. El primero de estos modelos concretos de poblamiento es el periurbano.

Este tipo de cuevas, aparecen normalmente en las cercanías de espacios de poblamiento al aire libre de cierta entidad, y vinculadas vías de comunicación que impulsan la relación de la cueva, con un movimiento de población desde los centros urbanos.

Otra de las características de estos yacimientos es su fuerte carácter agrícola, sobre una posible especialización ganadera. El entorno inmediato permite unos usos económicos mixtos pero siempre más vinculados a cultivos de cereal, con zonas de captación de agua siempre en las inmediaciones del yacimiento.

El material arqueológico hallado en estos yacimientos suele estar formado por abundante cerámica, quizás en unas proporciones mayores, a las de otros tipos de yacimientos, indicando posiblemente un uso doméstico más intensivo que otros espacios de tipo ganadero, a los que se recurre de forma puntual u ocasional.

Este modelo de ocupación aparece en la Edad del Hierro, si tenemos en cuenta el uso 
de algunas cuevas en el entorno inmediato de nuestros castros (Cueva del Hueso de Pillarno, la Corona de la Hería, el Castiello de Fozana...) ampliándose a la época romana (Eremitán, Entrellusa, valle de Santo Adriano) e intensificándose con un mayor número de yacimientos, en la época medieval, sobre todo en el entorno de Oviedo y sus vías de comunicación (El Fistru, Caldas, Buanga, Rondero) (Figura 14).

El otro modelo particular de ocupación, es el de los refugios o escondites. Hemos denominado así a un conjunto de cavidades cuya ubicación, de extrema dificultad de localización, así como su escaso registro material arqueológico parecen estar mostrando pautas de ubicación muy puntuales, en busca de un auténtico escondite visual, ajeno a una posible explotación económica del entorno.

En este pequeño grupo de yacimientos en cueva entrarían el Tinganón (Ribadesella), cueva del Río y la Foz (Caso), las cuevas de Viñayo y Orpiñas en León, así como posiblemente Cova Losa de Abajo, a las afueras de Oviedo.

El entorno inmediato de todas las cavidades citadas -a excepción de Cova Losa-, si bien es de montaña, con una localización de las cuevas y su acceso siempre bordeados por empinados barrancos, tampoco permite una fácil explotación ganadera del entorno.

El material cerámico hallado en estas cavidades es ínfimo en número si lo comparamos con otras de adscripción agropecuaria y periurbanas, lo que esta indicando un uso muy puntual o circunstancial de la cueva. Por otro lado, la factura del mismo, caso de las piezas descritas para el Tinganón, en Asturias, demuestra una cierta calidad técnica y decorativa, lo que podría estar reforzando la hipótesis de un uso puntual, por parte de grupos que están inmersos en un sistema de producción o circulación de bienes materiales más amplio.

A modo de curiosidad histórica, el uso repetido de estas cuevas también como refugios y escondites durante la guerra civil refuerza la hipótesis interpretativa que les hemos asignado respecto a su funcionalidad.

\section{La importancia de la arqueología inmaterial. El registro mitológico}

Es evidente que los espacios subterráneos han constituido en numerosas culturas lugares especiales en el plano ritual, mental y religioso, desde tiempos prehistóricos.

La oquedad natural que se abría camino hacia el interior de la tierra, con todo el simbolismo que esto supone en la mentalidad del hombre preindustrial, hace que las cuevas sean un espacio privilegiado en la documentación de los procesos de culto, y por lo tanto, sean unos lugares indispensables en la construcción de una arqueología de la religión.

Es fundamental subrayar la fuerte problemática que pesa sobre la documentación antropológica y sus interpretaciones actuales, para darnos cuenta de los vacíos temáticos que pueden afectar a nuestra síntesis. Así, la casi totalidad del material etnográfico parte de estudios parciales de ámbito muy local o de breves referencias sueltas en obras generales.

La realidad arqueológica de nuestras cavidades está íntimamente relacionada con la pervivencia del fenómeno mitológico; así, si bien es fundamental apartar el valor de lo literario para ahondar en el análisis histórico de ciertos mitos (GAZIN-SCHWARTZ y HOLTORF 1994), es indudable la conexión entre yacimientos arqueológicos y una mentalidad tradicional local, que desemboca en la explotación mitológica de esa realidad histórica.

Nuestra región está repleta de ejemplos a este respecto, abarcando desde dichos populares, caso de antiguas explotaciones de minería astur romana en el valle del Navia, hasta el caso de hallazgos de enterramientos en cueva del oriente de Asturias, cuya explicación popular se achaca a cementerios de los moros muertos por Pelayo (DE LLANO 1928: 22 y ALVAREZ PEÑA 2007):

"En Pescanti, los pescaron

en Copajenti, los coparon

en Mortuorio, los amortajaron

y en cuevajaviera los enterraron" 
En nuestra opinión, podríamos sintetizar en tres grandes fases el proceso evolutivo del uso cultual de nuestras cuevas en su pervivencia mítica, con una línea transformadora en el tiempo que puede definirse con claridad a partir de la cristianización.

I- En primer lugar, tendríamos una fase de cultos precristianos, con una plenitud de creencias vivas sobre las figuras mitológicas que residen en las cuevas.

2- La fase de cristianización supone tanto el cierre de "santuarios", la oficialización de los ritos, de otros, así como la conversión del mito pagano y su reversión funcional, convirtiendo por ejemplo a los antiguos "Janos" locales en diablos modernos a los que no se debe ofrecer rito alguno.

3- La fase contemporánea supone una ampliación del abandono de emplazamientos cultuales en cueva, incluyendo aquellos cristianizados y relegando al folklore infantil a los viejos mitos subterráneos, con una conversión de Diaños, xanas y Señoras (Urraca, Marica, Mari) en otros mitos residuales, como el sacamantecas, estripaor, sacauntos, diablos...

La cavidad es un espacio que representa el más allá en su sentido más pagano, en contraposición a un cielo cristiano, ajeno a los seres que "todavía" habitan en el subsuelo y de donde parten males que afectan a la comunidad, como el granizo o la sequía (SANZ 1991:54).

Este espacio es, por lo tanto, una zona de paso para el encuentro con los seres del universo mitológico tradicional (LLINARES 1990: 129), que mayoritariamente están emparentados con el mundo de los muertos, siguiendo un paralelismo con el averno clásico y que hacen del espacio donde viven un lugar de culto y comunicación con el más allá (DAVIDSON 1967: 145).

En este sentido destaca la leyenda asturiana del difunto que se casa en una cueva con la hija del diablo, invitando a su hermano vivo a la boda, el cual debe ir al evento provisto de reliquias como única forma de poder asistir al mismo y conseguir salir de la caverna (DE LLANO 1993: I48).
Si bien el concepto de la muerte es el que parece apoyar la casi totalidad de las manifestaciones cultuales y votivas de los espacios subterráneos, no podemos tampoco generalizar esta situación, ante las constantes pervivencias de ritos vitales de la comunidad que todavía se mantienen en algunas cuevas de Asturias, siendo un buen ejemplo el caso de Villamexín donde el último domingo de Semana Santa los niños iban tocados con cencerros hasta la cueva de la Maruxina, en busca de una xana quien concedería a la población local el deseo de obtener un buen bollo ese año (AA.VV, 1996, 74).

La concepción de más allá en base al mundo subterráneo queda bien definida en la mentalidad tradicional de numerosos pueblos, quienes creen que sus primeros antepasados han salido de una cueva (GRANDE DEL BRÍO 1982:23), como lugar por donde se marcharon "los antiguos", antes de la llegada de una nueva era marcada por la cristianización, como ocurre en el País Vasco (BARANDIARÁN 1979), o como adscripción popular de lugar de hábitat, de seres que originan los movimientos de la tierra como ocurre con los lobos sobrenaturales extremeños, causantes de los terremotos (DOMÍNGUEZ MORENO 1992:6).

Como contraposición a estas figuras malignas del mundo de los muertos nos encontraremos una figura del bien, representada a través de curas, curanderos, santos y héroes, los cuales son los únicos capaces de enfrentarse a los diferentes retos que ofrece un más allá invisible e intratable para el resto de los mortales.

Especial interés cobra la figura del "médico" de numerosas leyendas asturianas (DE LLANO 1993: 103), capaz de hablar con los muertos, tratar con ellos para predecir el futuro, y enfrentarse a los retos del diablo para favorecer a la comunidad, representando un papel de auténtico chaman dentro de la sociedad rural tradicional.

Desde el punto de vista geográfico, hay una clara delimitación de las figuras mitológicas subterráneas: en el valle del Duero y el cantábrico oriental nos encontramos con una figura femenina alejada de la xana astur, representada en el norte de Castilla (SANZ 1991:6) mayorita- 
riamente por la Virgen María y en el País Vasco por Mari; mientras, en la casi totalidad del área noroeste está representada en cambio por el binomio de las figuras de la xana y el moro, con el mito masculino del moro o diablo como figura principal del espacio subterráneo y que se extiende hasta parte de Extremadura y el Duero medio, lo que nos lleva a plantear la existencia de un contexto mitológico puramente atlántico.

Aparte de la fuerte carga mitológica, nos encontramos igualmente en nuestro trabajo de campo casos de brujería popular de difícil interpretación, como las pequeñas hogueras y bolas de tela en cuyo interior se situaba la cabeza cortada de una serpiente (las XanasOviedo), o los paneles de velas en la vecina Moratina (Oviedo).

Si a estos fenómenos le sumamos el uso de materiales geológicos de las cuevas en los ritos de curanderismo, las ofrendas y las procesiones que todavía se realizan en algunas de las cavidades estudiadas, nos hemos de plantear una potente cultura popular ancestral respecto a nuestras cavidades que, en cambio, es difícilmente detectable desde el punto de vista arqueológico y cuyo origen sigue siendo un misterio.

\section{Conclusiones para unas primeras observaciones de conjunto}

La primera conclusión de nuestro trabajo tiene como base la discusión del propio tratamiento del concepto de periferia o marginalidad, siendo necesario reconocer que los espacios que hoy observamos como periféricos, en su día fueron áreas accesibles y de una cierta vitalidad socio-económica.

Con una población envejecida y donde además los más jóvenes deciden emigrar o dedicarse a actividades no relacionadas con la ganadería, el paisaje de muchos valles de montaña esta transformándose a una velocidad que posiblemente no había sufrido hasta el momento.
¿Quien va a recordar la toponimia local en las zonas de pastos? ¿Serán estos lugares accesibles, con los caminos de ganado en desuso? Posiblemente convertidos en bosques, en menos de cincuenta años, a los investigadores que intenten interpretar el paisaje a partir de ese momento les será imposible concebir la idea de unos grupos humanos que desarrollaban casi toda su actividad diaria y económica en muchos de esos parajes. Se convierten entonces para el investigador en áreas "marginales", dentro de un concepto claramente discutible, que podemos trasladar a nuestro propio estudio.

Fuera ya de una discusión de conceptos, la problemática del tema que hemos tratado es enorme, con una falta total de nuevos hallazgos a partir de nuestra revisión de las cuevas, y donde, si bien hemos podido aportar algún yacimiento nuevo, la calidad de los datos constituye un catálogo endeble de suposiciones arqueológicas sobre las que crear nuestras propias interpretaciones.

Con apenas dos cuevas, de todo el corpus de yacimientos estudiados, excavadas mediante una técnica arqueológica fiable (ENTRELLUSA y EREMITÁN), y con sólo una de ellas que haya aportado datos materiales en esas intervenciones (ENTRELLUSA) (ADÁN y otros 2004), las posibilidades de establecer comparaciones entre yacimientos de una misma tipología o función son nulas.

Pese a ello, con todos los vacíos materiales fiables achacables en nuestro catálogo base, consideramos que se pueden extraer ciertas observaciones de interés.

Partimos, en contra de las líneas propuestas hasta el momento, de la interpretación de los espacios subterráneos de nuestro ámbito de estudio, dentro de una diversidad de modelos y multiplicidad de situaciones en un mismo yacimiento. No consideramos, por lo tanto, la ocupación de las cavidades dentro de un fenómeno general, mezcla de espacios ganaderos temporales, de una supuesta tradición habitacional prerromana o de refugios en momentos de crisis. La explicación del fenómeno es individual a cada yacimiento y a la calidad de su registro, 
con lo que cada cueva es discutida según sus características, hasta formar parte de un mapa general, por épocas y posibles funciones.

Se discute por vez primera el contexto protohistórico de muchas de las cuevas asturleonesas, basándonos tanto en factores de ubicación como en la existencia, también en nuestro ámbito de estudio, de unas producciones cerámicas a mano de época altomedieval, que hasta el momento eran tratadas como material cerámico protohistórico.

Planteamos una identificación funcional de las cuevas estudiadas en base a su localización geográfica, las posibilidades económicas de sus entornos inmediatos, su accesibilidad y el repertorio de hallazgos localizados en las mismas. Esta línea de trabajo nos lleva a proponer una identificación funcional y cronológica de todos los casos estudiados que en muchos casos choca de lleno con las interpretaciones tradicionales que se les habían asignado.

Nuestro corpus de yacimientos protohistóricos en cueva demuestra una total falta de tradición habitacional o funcional de dichos yacimientos respecto a épocas posteriores.

A partir de esta discusión, presentamos la idea de una primera red de cuevas de alta montaña, ocupadas entre la tardoantigüedad y la época hispano-visigoda que, lejos de constituir lugares de refugio, las interpretamos como estructuras a modo de cuevas-braña e incluso como pequeños establecimientos agropecuarios de producción mixta, en aquellos lugares que no se encuentran en zonas de montaña, caso del valle medio del Nalón.

Las mínimas tesaurizaciones, así como los escasos hallazgos numismáticos individuales en cueva, producto éstos de una posible ocupación doméstica puntual, muestran la casi nula presencia de cultos subterráneos, siendo casi inexistentes los hallazgos de este tipo respecto a otro tipo de ocupaciones. Las cuevas asturleonesas apenas contienen un sentido cultual durante la época romana, salvo en algún caso muy excepcional, que puede deberse a su ubicación anexa a una vía de comunicación (El Ferrán).
Las únicas manifestaciones rituales que se dan en nuestras cuevas aparecen dentro del ámbito funerario, dentro de un contexto cultual muy concreto, producto de influencias orientales, y siguiendo una tradición ritual tardoantigua, permeable a influencias continentales, durante el período visigodo. Esta situación, que se desarrolla en el cantábrico de forma muy local, muestra el poder socioeconómico de los grupos de montaña, lejos de la tradicional marginalidad sociocultural que les hemos asignado, debido a su ubicación geográfica, dentro de esa supuesta "Edad Oscura".

Para el caso de las cuevas-braña, la continuidad de la secuencia material, así como la repetición de esos factores de ubicación en la posterior época medieval nos lleva a plantear una continuidad del modelo tardoantiguo, cuya tradición funcional en el uso de las cuevas como brañas llega hasta nuestros días.

Planteamos la posible existencia de una secuencia evolutiva en determinados valles de montaña, donde esas cuevas-braña, o incluso algunas cuevas con entornos agrícolas, forman el origen de las posteriores aldeas que se hallan en sus inmediaciones. Las cuevas constituirían unas primeras brañas, a partir de las cuales se establecen en algunos casos estructuras al aire libre y posteriormente auténticas aldeas (Figura 15).

\section{BIBLIOGRAFÍA}

AAVV. (1996): Tradiciones y leyendas del valle del Trubia. Oviedo.

ADAN ALVAREZ, G. E., ARBIZU, M., ALVAREZ LAO, D., CARRETERO, J. M ${ }^{\mathrm{a}}$., CID, R. M ${ }^{\mathrm{a}}$., GARCIA ALVAREZ, A., RODRIGUEZ, L., GARCIA, R., IBAÑEZ, C., PALACIOS, X. y ALVAREZ, D. (2004): "La playa d'Entrellusa (Perlora): del paleolíticu a los enterramientos tardorromanos, la construcción na Islla y la caza de ballenes nel medievu". Asturies, 18. pp. 16-23.

ABASOLO ALVAREZ, J. A. y PEREZ RODRIGUEZARAGON, F. (1995): "Arqueología funeraria en Hispania durante el Bajo imperio y la época visigoda". Arqueoloxía da morte. Arqueoloxía da morte na Península Ibérica desde as orixes ata o medievo. Xinzo de Limia: 293-205. 
ALVAREZ PEÑA, A. (2007) "Mitos y folklore de las cuevas asturianas". Estudios varios de arqueología castreña. A propósito de las excavaciones en los castros de Teverga, Asturias. Salamanca.

ARIAS CABAL, P. (|99|): De cazadores a campesinos. La transición al neolítico en la región cantábrica. Santander.

AVELLO, J. L. (1985-86): "El jarrito hispano-visigodo de Alesga y algunas consideraciones generales sobre estos objetos liturgicos". Asturiensia Medievalia, 5: 19-32.

AZCARATE GARAI-OLAUN,A. (1988): Arqueología de la antigüedad tardía en Alava, Guipuzcoa y Vizcaya. Vitoria.

AZCARATE GARAI-OLAUN,A. y SOLAUN BUSTINZA, J. L. (2008): "Excavaciones arqueológicas en el exterior de los conjuntos rupestres de las Gobas (Laño, Burgos)". Archivo español de arqueología, 81: |33-|49.

BALLESTEROS VILLAR, F. (2002): Pastores y majadas del Cornión. León.

BARANDIARAN, J. M. de (1979): Mitología Vasca. San Sebastián.

BARBERO, A. y VIGIL, M. (1978): La formación del feudalismo en la Península Ibérica. Barcelona.

BARRAU-DIHIGO, L. (1919-1920): Manuel de I'hispanisant. Tomo II. Paris.

BERROCAL-RANGEL, L., MARTINEZ SECO, P. y RUIZ TRIVIÑO, C. (2002): El Castiello de Llagú (Latores, Oviedo). Un castro astur en los orígenes de Oviedo. Madrid.

BOHIGAS ROLDAN, R. (1999): "La arqueología de la Alta Edad Media en Cantabria". Regio Cantabrorum. Santander: 36|-37|.

BOHIGAS ROLDAN, R. y RUIZ GUTIERREZ, A. (1989): "Las cerámicas visigodas de poblado en Cantabria y Palencia". Boletín de arqueología medieval, 3: 31-5l.

BRAMWELL, D. y otros (1983): "Excavations at Poole's cavern, Buxton. An interim report. Derbyshire Archaeological Journal, 103: 47-74.

BRANIGAN, K. y BAYLEY, J. ( 1989): "The Romano-British Metalwork from Poole's cavern, Buxton". Derbyshire Archaeological Journal, 109: 34-50.

BRANIGAN, K. y DEARNE, M. J. ( I999): Romano-British cavemen. Cave use in Roman times. London.

DAVIDSON, H. R. E. (1967): Pagan Scandinavia. Nijmegen.

DIEGO SANTOS, F. (1978): Historia de Asturias. Asturias romana y visigoda. Salinas

DOMINGUEZ MORENO, J. M. (1992): "La divinización del lobo en Extremadura". Revista de Folklore, 12. Tomo II: 3-9.

ESCORTELL PONSODA, M. (1975): Catálogo de las salas de cultura romana del museo arqueológico de Oviedo. Oviedo.

ESTEPA DIEZ, C. (1998): "Comunidades de aldea y formación del feudalismo. Revisión de la cuestión y perspectivas". "Romanización" y "Reconquista" en la Península Ibérica. Nuevas perspectivas. Salamanca: 27I-282.
ESTRADA GARCIA, R., JORDA PARDO, J.F., CHAO ARANA, F.J y RIOS GONZALEZ, S (1997): Inventario arqueológico del concejo de Parres. Consejería de Cultura del Principado de Asturias. Inédito.

FABREGAS VALCARCE, R. (1995): "La realidad funeraria en el noroeste del Neolítico a la Edad del Bronce". Arqueoloxía da morte. Arqueoloxía da morte na Península Ibérica desde as orixes ata o medievo. Xinzo de Limia: 97-II9.

FANJUL PERAZA, A., FERNANDEZ RODRIGUEZ, C., LOPEZ PEREZ, M. C. y ALVAREZ PEÑA, A. (2007): "Excavaciones en el castro de la Garba (Teverga), Asturias. Primeros trazos arqueológicos del poblamiento castreño en la alta montaña". Estudios varios de Arqueología castreña A propósito de las excavaciones en los castros de Teverga, Asturias. Salamanca.

FERNANDEZ MANZANO, J. y ARIAS CABAL, P. (1999): "El Bronce Final en el territorio de los antiguos cántabros". Regio Cantabrorum. Santander: I- 12.

FERNANDEZ MIER, M. y FERNANDEZ HEVIA, J. M. (1998): "Un microespacio en la montaña asturiana: Presorias". Arqueología y territorio medieval, 5: 91-107.

FIGUEROLA, M. G. de (1984-1985): "Una tumba tardoromana con ajuar en Valverde del Fresno (Cáceres)". Zephyrus, XXXVII-XXXVIII: 370-375.

GAZIN-SCHWARTZ, A. y HOLTORF, C. (eds) (1999): Archaeology and Folklore. London.

GONZALEZ RODRIGUEZ, Ma. C. (1997): Los astures y los Cantabros Vadinienses. Vitoria.

GRANDE DEL BRIO, R. (1982): "La cueva de la Quilana". Revista de Folklore, 2. pp. 23-25.

GUTIERREZ GONZALEZ, J. A. (1985): Poblamiento antiguo y medieval en la montaña central leonesa. Diputación provincial de León. León.

GUTIERREZ GONZALEZ, J. A. y RODRIGUEZ VAZQUEZ,A. (2003): "Cerámica”. Peñaferruz (Gijón). El castillo de Curiel y su territorio. Gijón: I67-230.

HIERRO GARATE (2002): "Arqueología de la tardoantigüedad en Cantabria: yacimientos y hallazgos en cueva", Nivel Cero, 10. Santander: I13-128.

LALIENA, C. y ORTEGA, J. (2005): Arqueología y poblamiento. La cuenca del río Martín en los siglos V-VIII. Colección Mancuso, 2. Teruel.

LLANO ROZA,A. de (1928): Bellezas de Asturias. Oviedo.

(1993) (reedición): Cuentos asturianos recogidos de la tradición oral. Oviedo.

LLINARES, M. M. (1990): Mouros, ánimas, demonios. El imaginario popular gallego. Madrid.

MAÑANES,T. (1988): Arqueología de la cuenca leonesa del rio Sil (Laceana, Bierzo, Cabrera). Serie arte y arqueología, 6. Universidad de Valladolid.Valladolid.

-(1990):"Protohistoria y romanización en la provincia de León". Portugalia, 23: I53- 175. 
MARTINVISO, I. (2000): Poblamiento y estructuras sociales en el norte de la Península Ibérica. Siglos VI-XIII. Acta Salmanticensia, Estudios históricos y geográficos III. Universidad de Slamanca. Salamanca.

MARTINEZ, A. y UNZUETA, M. (1988): Estudio del material romano de la cueva de Peña Forua (Forua-Vizcaya). Bilbao.

MAYA GONZALEZ, J. L.(1989): Los castros en Asturias. Oviedo.

-(1996): "Cerámicas de época celtibérica en la Edad del Hierro asturiana". Pyrenae, 27: 287-294.

MENENDEZ BUEYES, L. R. (200I): Reflexiones críticas sobre el origen del reino de Asturias. Acta Salmanticensia, estudios históricos y geográficos, I14. Universidad de Salamanca. Salamanca.

-(2006):"'La geografía del poder en la cantabria tardoantigua: desde el final del imperio romano a la conquista visigoda (siglos V-VIII)". El ciclo histórico del Beato de Liébana. Santander: 27-44.

PALOL, P. (1954): "Arqueología paleocristiana y visigoda". IV congreso internacional de ciencias prehistóricas y protohistóricas. Zaragoza: 3-4I.

PEREZ RODRIGUEZ-ARAGON, F. (1999):" La antigüedad tardía en la Cantabria meridional". Regio Cantabrorum. Santander: 34|-350.

PUERTAS TRICAS, R. (1965): "El eremitismo rupestre de la zona de Nájera". IX Congreso Nacional de arqueología. Valladolid: 419-430.

QUIROS CASTILLO, J. A. (2006):. “La génesis del paisaje medieval en Alava. La formación de la red aldeana". Arqueología y territorio medieval, I 3.1: 49-94.

QUIROS CASTILLO, J.A. y ALONSO MARTIN, A. (2008): Las ocupaciones rupestres en el fin de la antigüedad. Los materiales cerámicos de los Husos. (Elvillar, Alava). Veleia, 24-25: | | 23-। | 42 .

QUIROS CASTILLO,J.A. y BENGOETXEA REMENTERIA, B. (2006): Arqueología postclásica. Universidad nacional de educación a distancia. Madrid.
RODRIGUEZ RESINO, A. (2008): "Comunidades rurales, poderes locales y señorío episcopal en la tierra de Santiago delos siglos $\mathrm{V}$ a XI: una visión desde el registro arqueológico". Munibe, 59: 219-245.

SANZ, I. (|99|): "Leyendas segovianas". Revista de Folklore, II: 5 I -57.

SERNA, A., VALLE, M. A. y MORLOTE, J. (1992): "Las cuevas con restos ocupacionales de la Edad del Hierro". La arqueología de los cantabros. Santander: 97-III.

SERNA, A., VALLE, M. A. y HIERRO GARATE, J. A. (2005): "Broches de cinturón hispanovisigodos y otros materiales tardoantiguos de la cueva de las Penas (Mortera, Piélagos)". Sautuola, XI: 247-276.

SOLAUN BUSTINZA, J. L. (2005): La cerámica medieval en el País Vasco (siglos VIII-XIII). Vitoria.

SUAREZ OTERO, J., GIMENO, R. G. y FARIÑA BUSTO, F. (1989): "La cerámica medieval en Galicia". La cerámica medieval en el norte y noroeste de la Península Ibérica. Aproximación a su estudio. León: 285-295.

SUAREZ SARO, A. (1980): Excavaciones en el Cantu del Rey, Faro. Inédito.

TOLEDO CAÑAMERO, Ma del C. (1999): "Panorama científico en las investigaciones sobre la producción cerámica de la Edad del Bronce en Cantabria". Regio Cantabrorum. Santander: 13-20.

VALLADARES ALVAREZ, J. A. (2005): El brañeo en Asturias. Oviedo.

VIGIL-ESCALERA GUIRADO, A. (2000): "Cabañas de época visigoda: evidencias arqueológicas del sur de Madrid. Tipología, elementos de datación y discusión". Archivo español de arqueología, 73: 223-252.

-(2007): "Granjas y aldeas altomedievales al norte de Toledo (450-800 d. C.)". Archivo español de arqueología, 80: 239-284. 


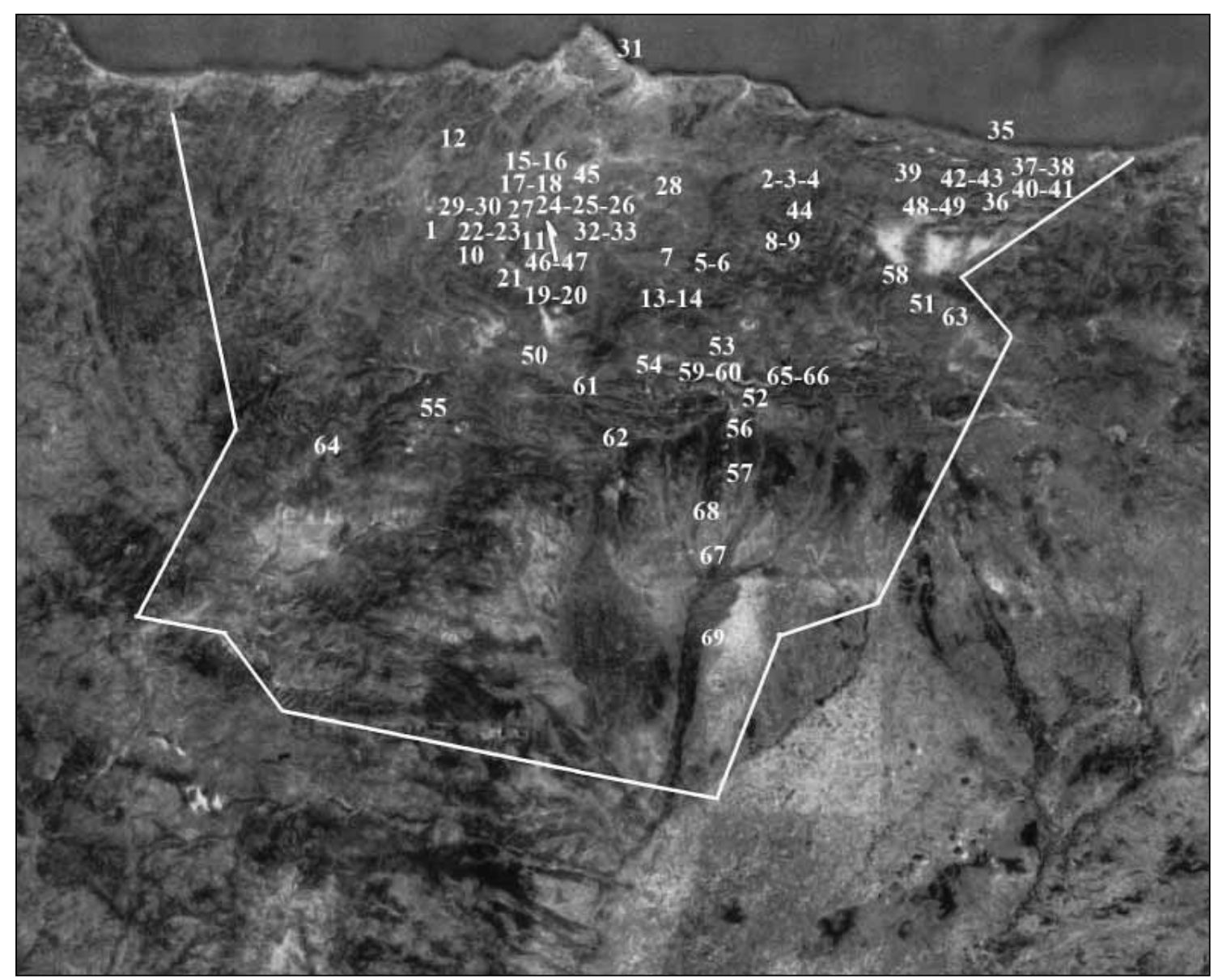

Figura I. Cuevas estudiadas con ocupaciones históricas.

ASTURIAS: I-El Collau, Dolia. 2-El Greyu, Sinariega. 3-Copilae, Las Coronas. 4-Laspru, Aballe. 5-La Foz, Venero. 6-Cueva del río, Venero. 7-Les Xanes, Tornos. 8-Barbaroña, Priesca. 9-Les Beleñes, Priesca. 10-Chapipi, La AsnieIla. I I-Castro Blanco, Santo Adriano del Monte. I2-Cueva Grande, Zorrina. I3-Rondero, Cuevas. I 4-La Salona, Conforcos. 15-La Andina, Taoces. I6-La Paloma, Soto. 17-Cueva Oscura, Ania. I8-Sofoxó, Nora. 19-La Chinariega A, Páramo. 20-La Chinariega B, Páramo. 21 -Cueva Huerta, Fresnedo. 22-Cueva Cuartel, Hedrada. 23-Trichacueva, Campiello. 24-El Fistru, Palomar. 25-Cova Losa, Priorio. 26-Las Caldas, Priorio. 27-Buanga, San Andrés. 28-Cueva del Castro, Fozana. 29-Cadén, Vendillés. 30-Prendada, Foxó. 3 I-Entrellusa, Perlora. 32-Cuave Cabrera, Figares. 33-Pico Castiello, Parteayer. 34-Xinxanganas, Sucueva. 35-Cueva de Pueblo Bajo de Lledías. 36-El Palacio, Mere. 37-El Covarón, La Pereda. 38-Ordaliega, Vidiago. 39-Tinganón, Llovio. 40-Las Brujas, Alles. 4 I-Cueva Negra, Llonín. 42- Poo. 43-Calluanga, Arenas. 44-Peña Ferrán, Ferrán. 45-Eremitán, Llagú. 46-Rebollal, Santo Adriano. 47-La Covona, Santo Adriano. 48-El Milagro, Santa María. 49, Cueva Pequeña, Carreña.

LEON: 50-El Arroyo, Barrios de Luna. 5 I-Orpiñas, Llanaves. 52-La Cudrera, Collé. 53-Covachos, Canseco. 54-Las Cuevas, Cuevas de Viñayo. 55-Peñalacasa, Morla. 56-La Prida, La Velilla. 57-El Cubo, Rueda. 58-Buseco, Oseja de Sajambre. 59-Sanchuzano de Gerás. 60-La Feliciana, Gerás. 61 -Los Ladrones, Paradilla. 62-San Mateo, Pola de Gordon. 63-Abrigos de Corona, Cordiñames de Valdeón. 64-Las Cuevas, Corporales. 65-El Fontanón II, Nocedo de Curueño. 66-El Fontanón III, Nocedo de Curueño. 67-Cuevas Menudas, Villasabariego. 68-San Martín, Villamoros. 69-Cueva de los Moros, Valle de Mansilla. 


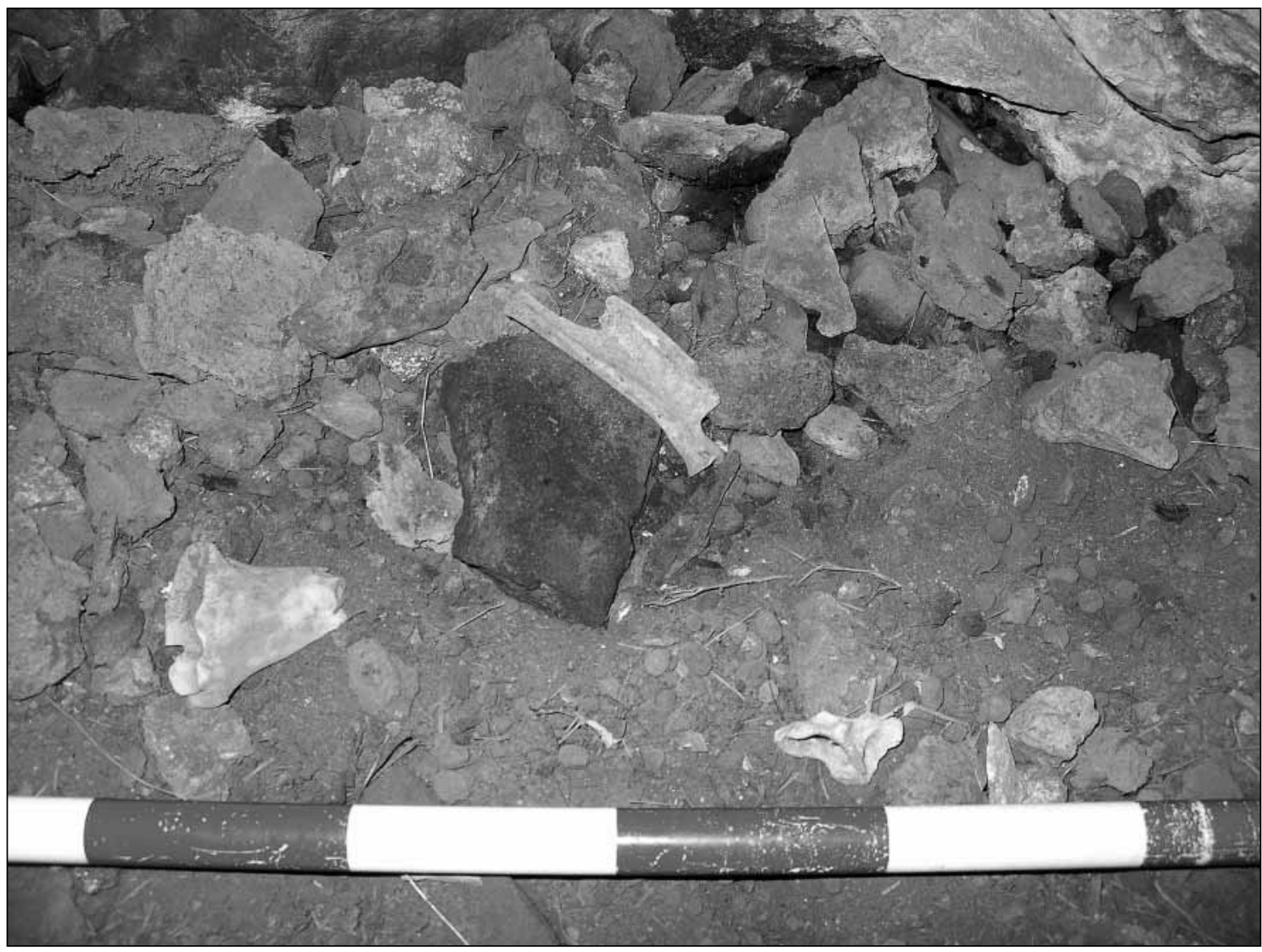

Figura 2. Pese a la visita pormenorizada de los yacimientos arqueológicos que forman parte de nuestro estudio, apenas es posible aportar datos nuevos en el plano material. Lo exiguo de los restos hallados, así como sus dudas cronológicas, caso de estos restos óseos en la superficie de la cueva medieval del Colláu en Belmonte de Miranda, muestran una de las principales dificultades a la hora de abordar la interpretación de estos yacimientos.

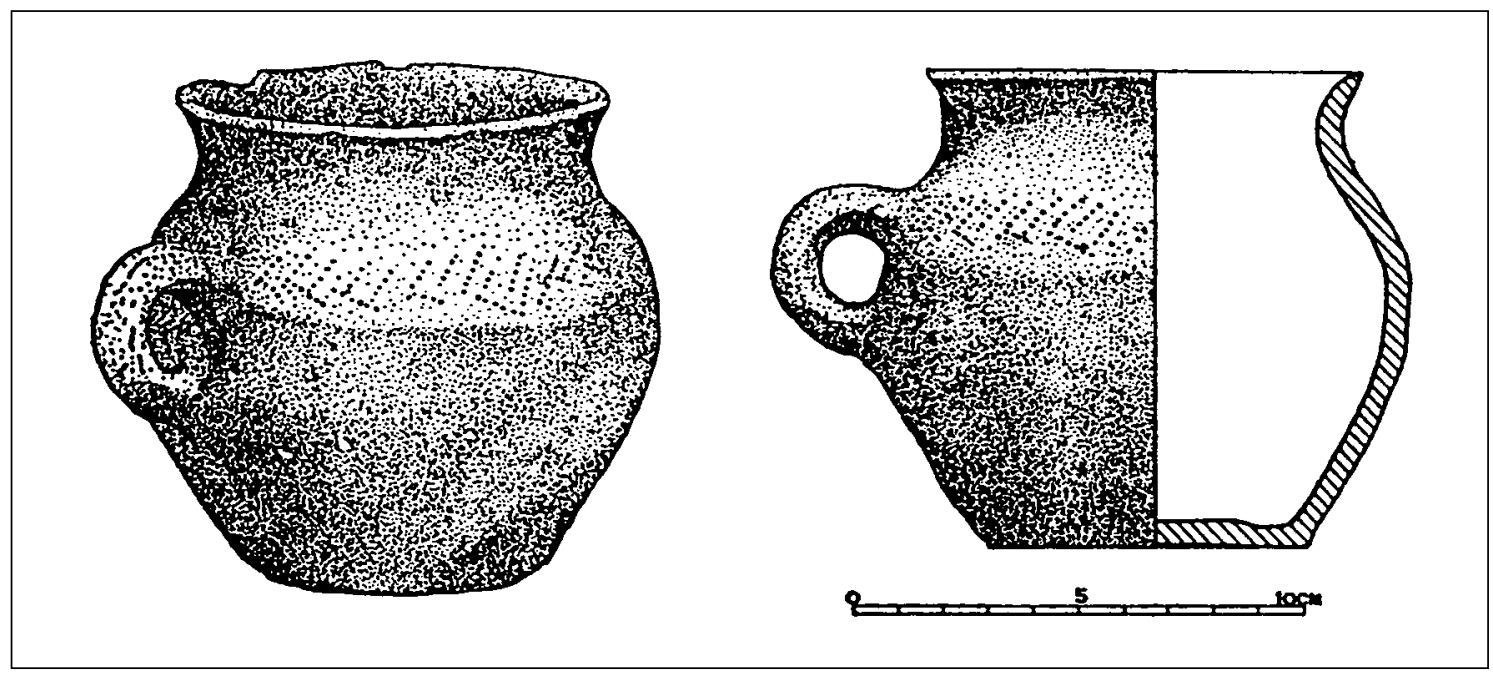

Figura 3. Una de las piezas de la cueva de la Zurra (Arias, Pérez y Trevín 1986, 241 y Maya 1996, 289). Su origen tecnológico local, fuera de un contexto claramente protohistórico, como hallazgo arqueológico, hace que surjan dudas, sobre su filiación prerromana, planteándonos su contexto tardoantigüo o hispano-visigodo. 


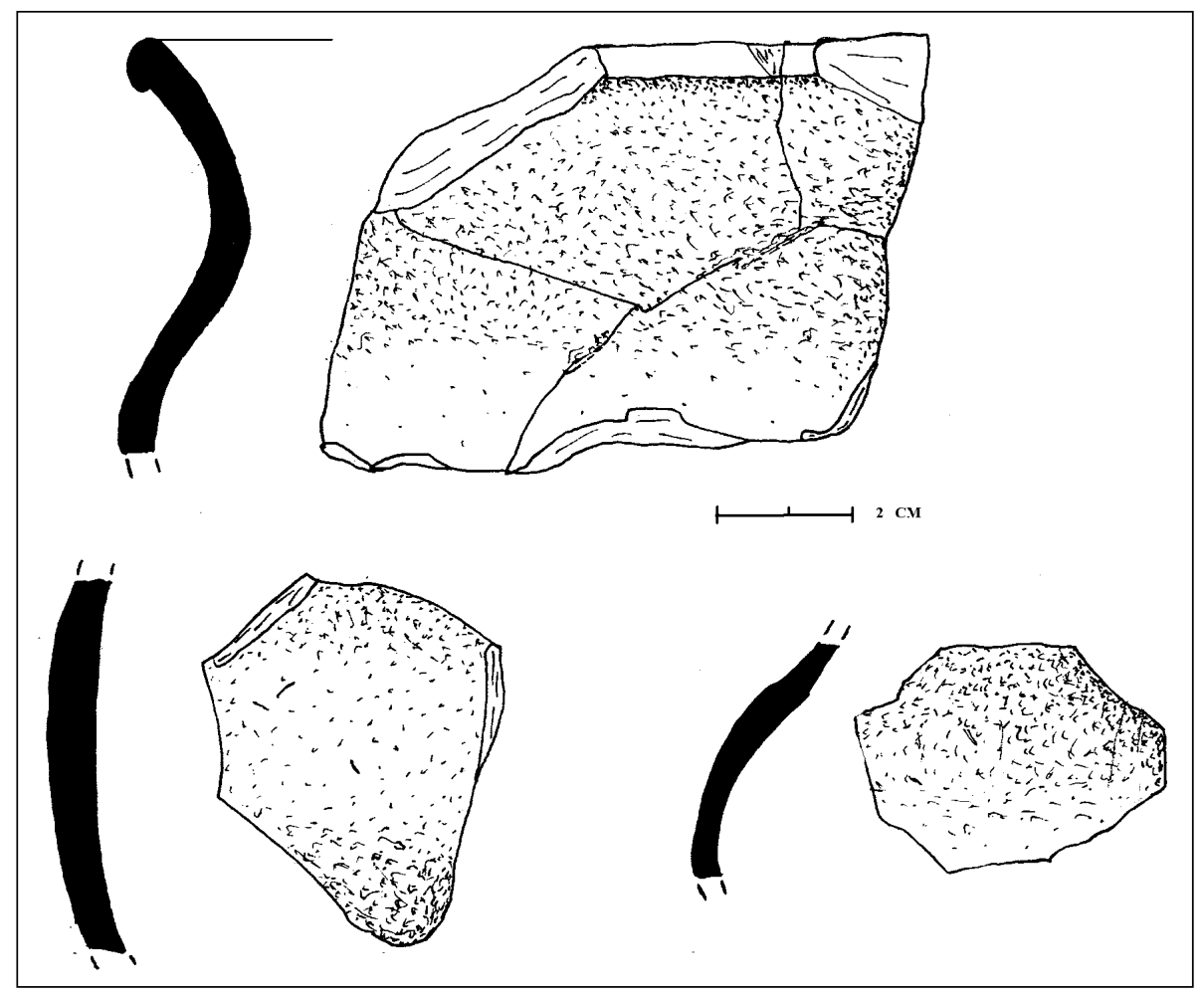

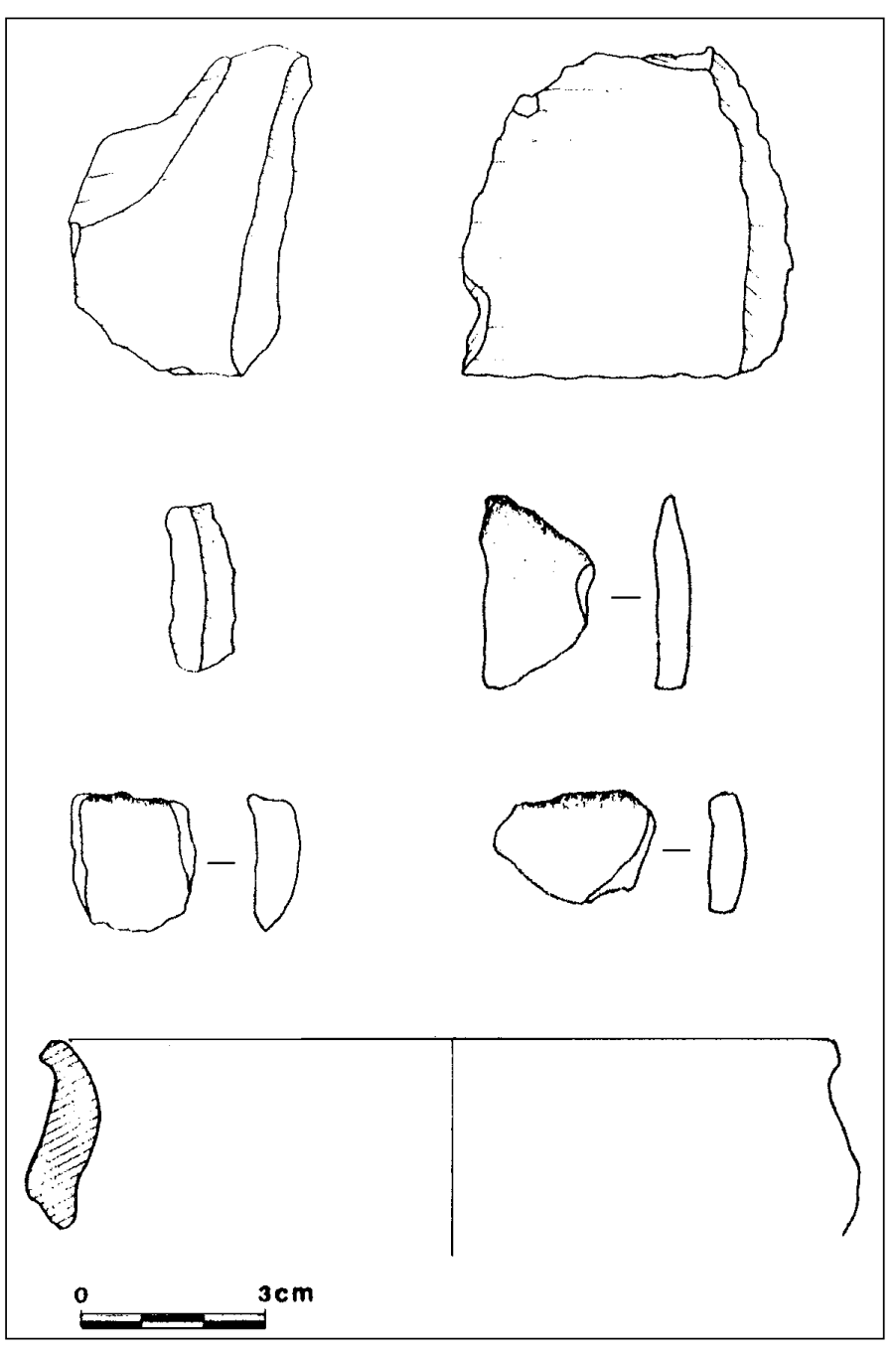

Figura 4. Materiales cerámicos a mano del Greyu (Estrada y otros,

1995), cuyas formas y contexto geográfico del yacimiento, creemos que apuntan a cronologías altomedievales y no protohistóricas, como tradicionalmente se les ha asignado.
Figura 5. Materiales líticos y cerámicos de Cueva Zorrina (Rodríguez y Camino 1989). La mezcla de las producciones manuales o escasamente torneadas, con restos líticos, han llevado a plantear un contexto protohistórico de muchas de las cuevas analizadas. Las dudas respecto a esos materiales cerámicos, exigen un proceso de revisión de dichos contextos cronoculturales. 


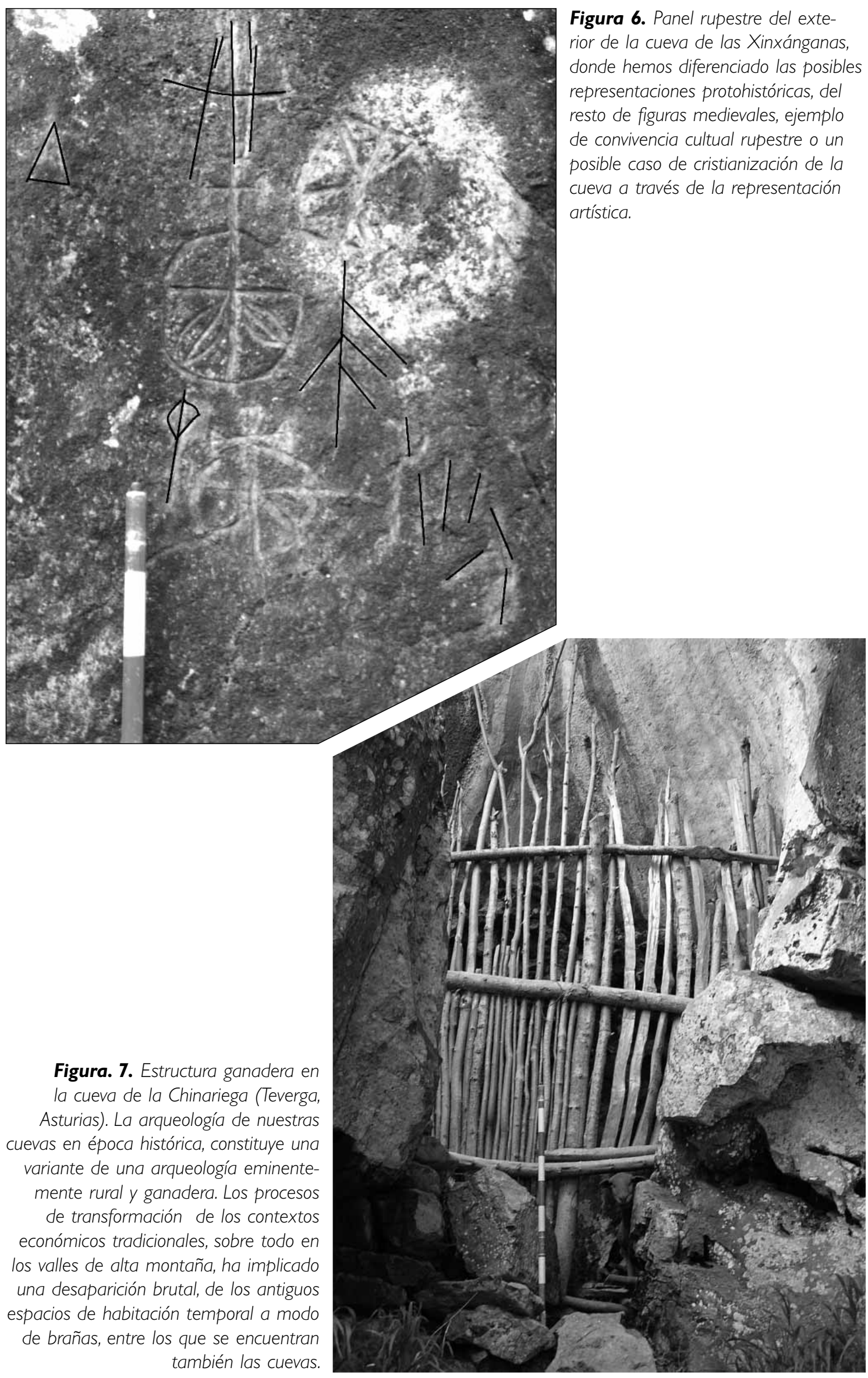




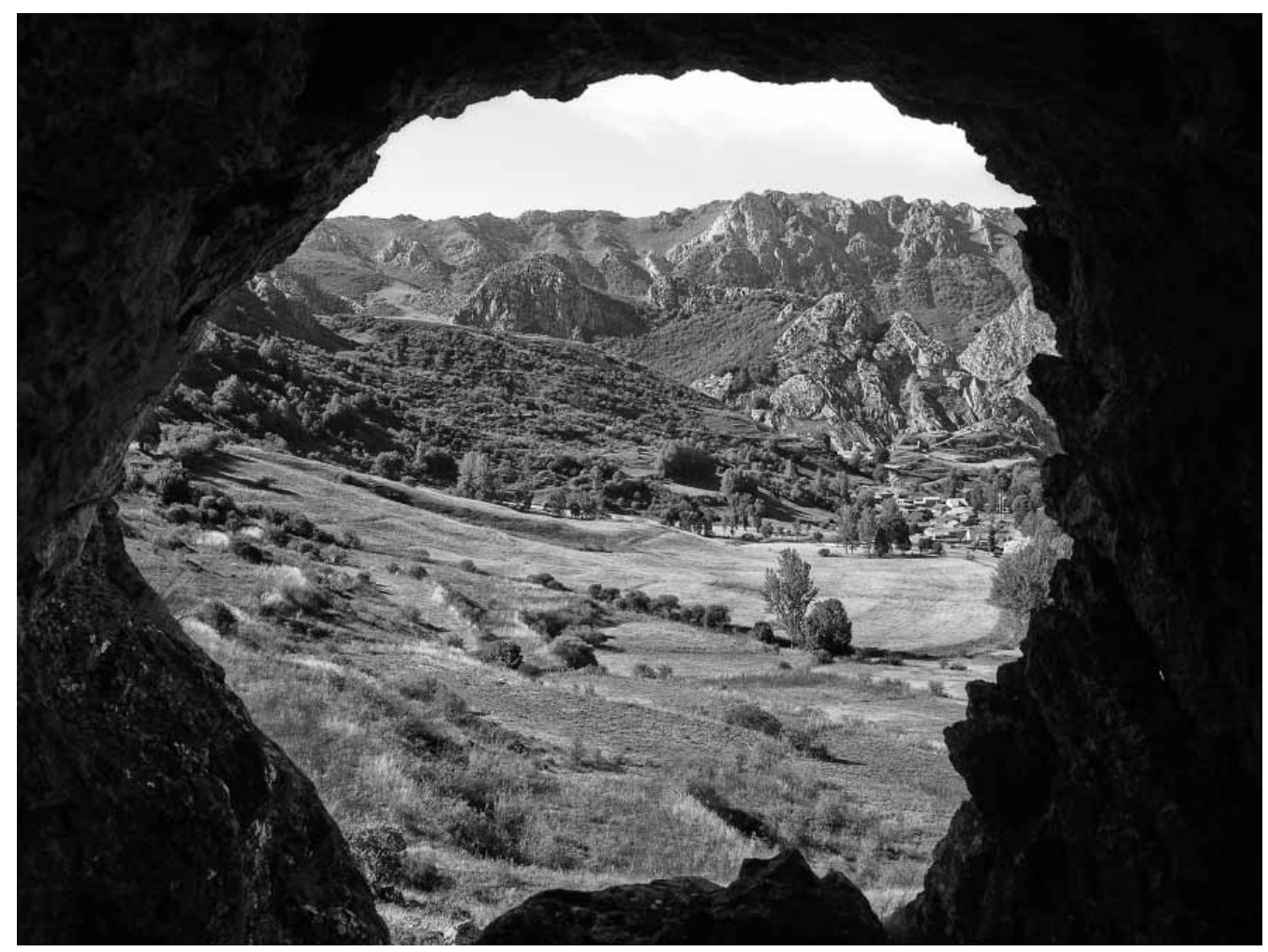

Figura 8. El entorno inmediato de muchas cavidades como esta, de Covachos de Canseco, en León, suele permitir una explotación mixta del territorio, mediante terrazas agrícolas y áreas exclusivamente ganaderas.

Figura 9. Repertorio cerámico recuperado en les Beleñes, (Sánchez y Menéndez 2000).

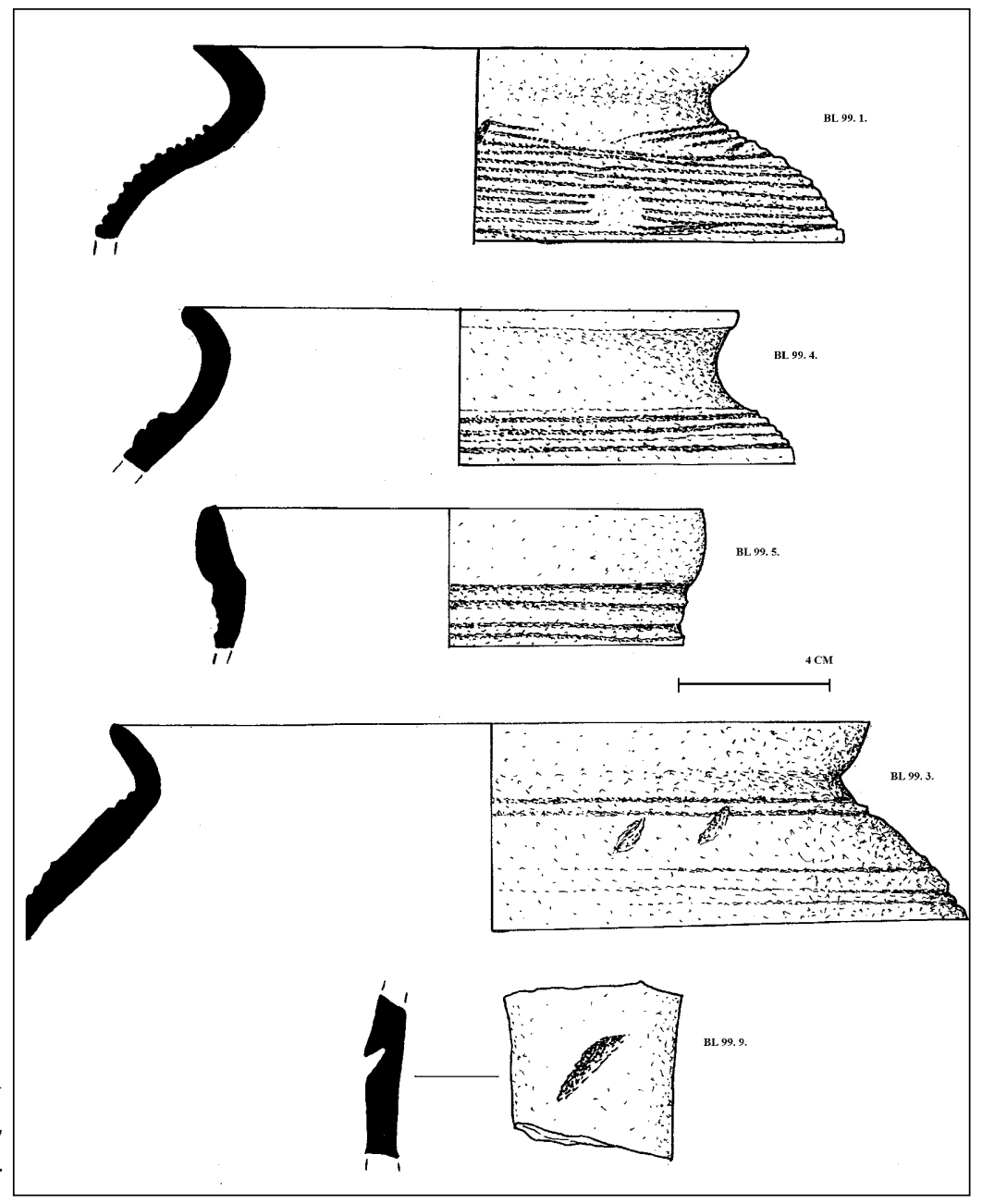




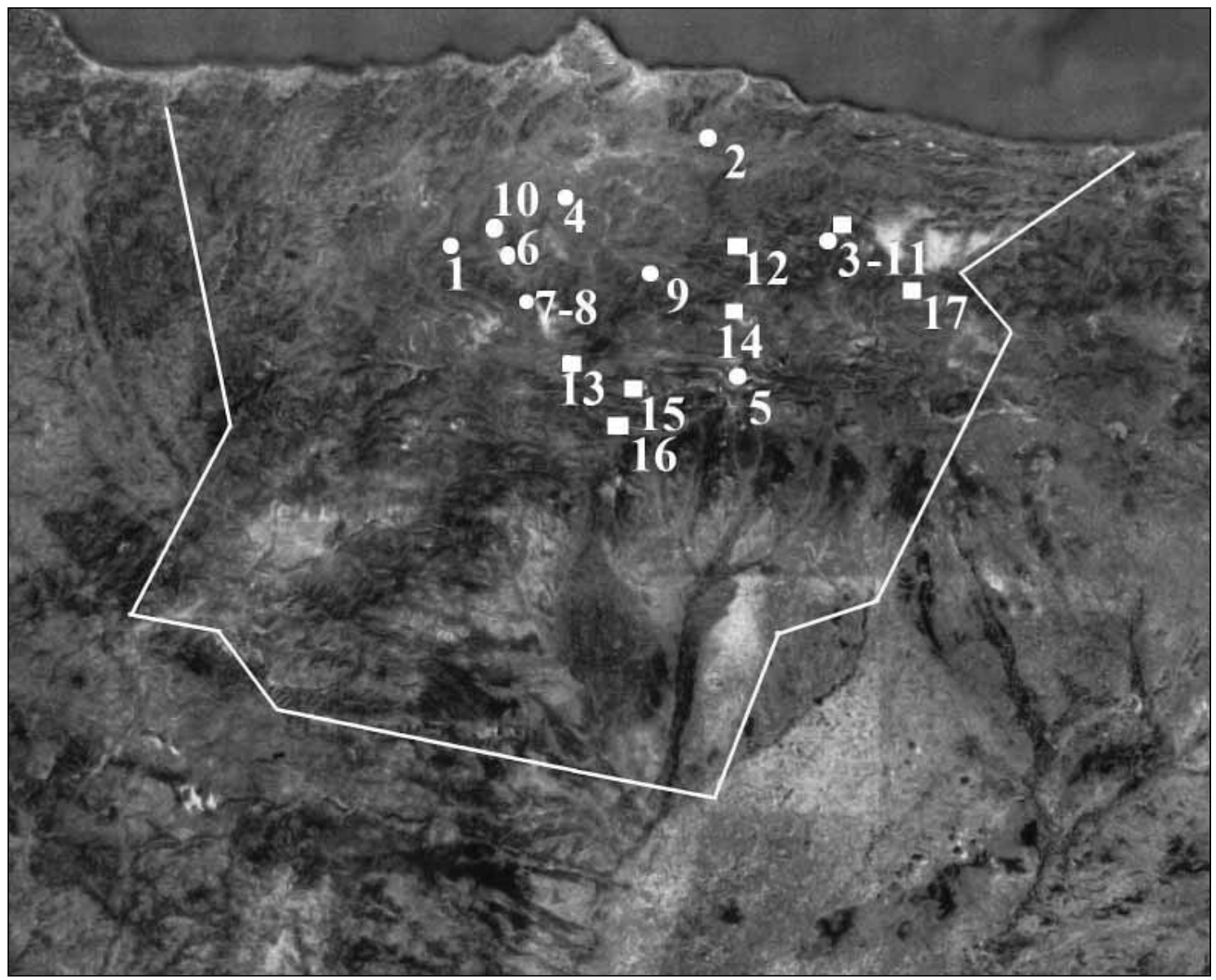

Figura I0. Cuevas-Braña de época medieval.

Dentro de este tipo de hábitat, observamos dos grupos, por un lado, aquellos yacimientos cuyo entorno inmediato es puramente ganadero, representados por un círculo, y aquellos de entornos con usos mixtos, tanto ganaderos como agrícolas (cuadrados).

En líneas generales, se observa una mayor capacidad de usos mixtos, en las cuevas leonesas, salvo un par de excepciones de la alta montaña asturiana, donde hemos atestiguado cultivos de cereal en el entorno de dichas cuevas, hasta épocas recientes.

I- El Collau, Dolia. 2- Laspru, Aballe. 3- Barabroña, Priesca. 4- Cueva Cabrera, Figares. 5- El Fontanón II, Nocedo. 6-Cuacuartel, Hedrada. 7-Chinariega B, Páramo. 8-Chinariega A, Páramo. 9-La Salona, Conforcos. I0-Castro Blanco, Santo Adriano. II -Les Beleñes, Priesca. I 2-Les Xanes, Tornos. 13 -El Arroyo, Barrios de Luna. I4-Covachos de Canseco. 15-Sanchuzano de Gerás. I6-San Mateo, Pola de Gordón y 17. Abrigos de Corona, Cordiñames de Valdeón. 


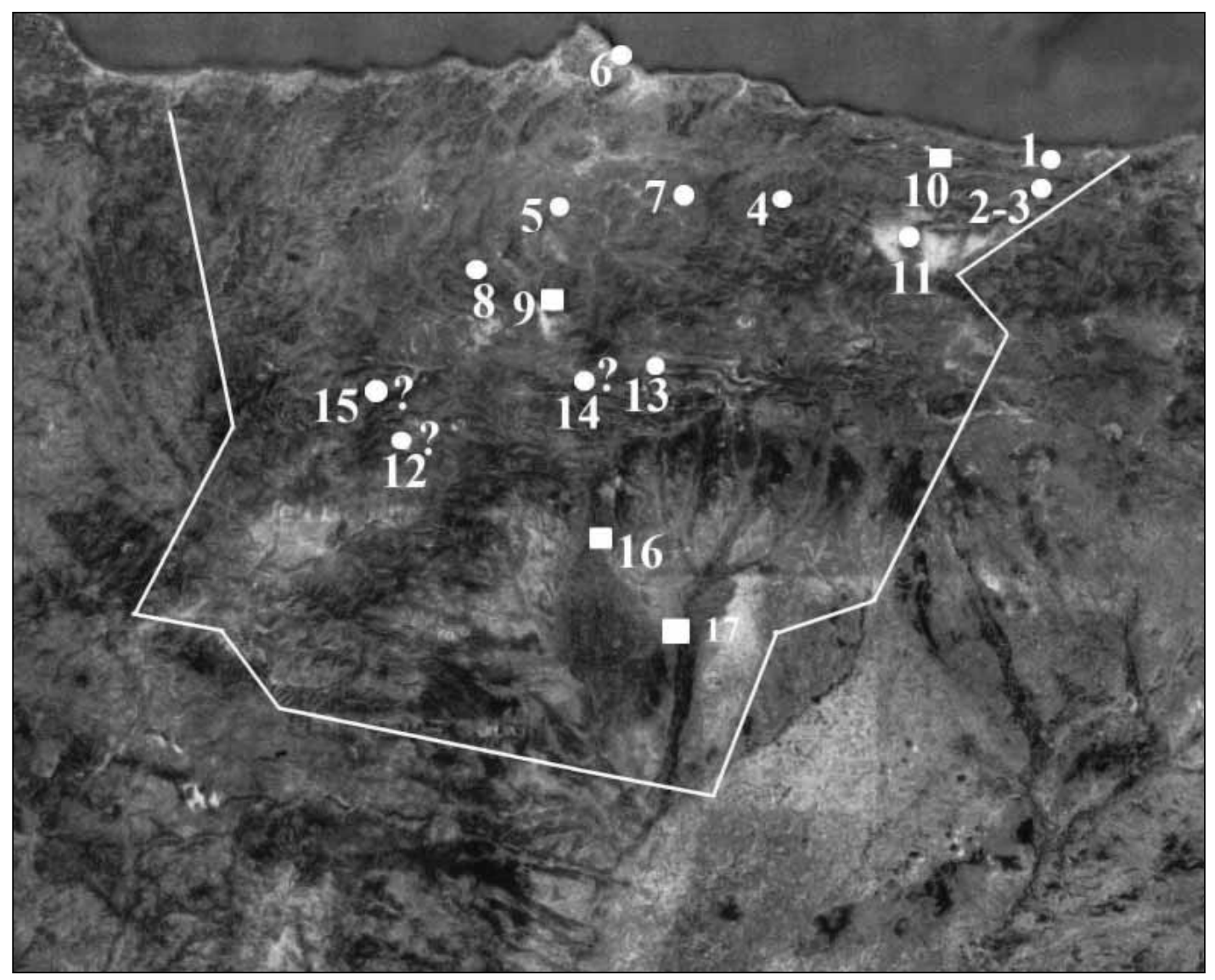

Figura II. Cavidades con usos funerarios o religiosos de época astur-romana (círculos) y visigoda (cuadrados).

I-Pueblo Bajo de Lledías. 2-Las Brujas, Alles. 3-Cueva Negra, Llonín. 4-Peña Ferrán, Ferrán. 5-Rebollal, Santo Adriano. 6-Entrellusa, Perlora. 7-Cueva del Castro, Fozana. 8-Trichacueva, Campiello. 9-Cueva Huerta, Fresnedo. 10-El Milagro, Santa María. I I-Cueva Pequeña, Carreña. I2-Peñalacasa, Morla. I3-La Feliciana, Gerás. I4-Los Ladrones, Paradilla. I5-Las Cuevas, Corporales. I6-San Martín, Villamoros.

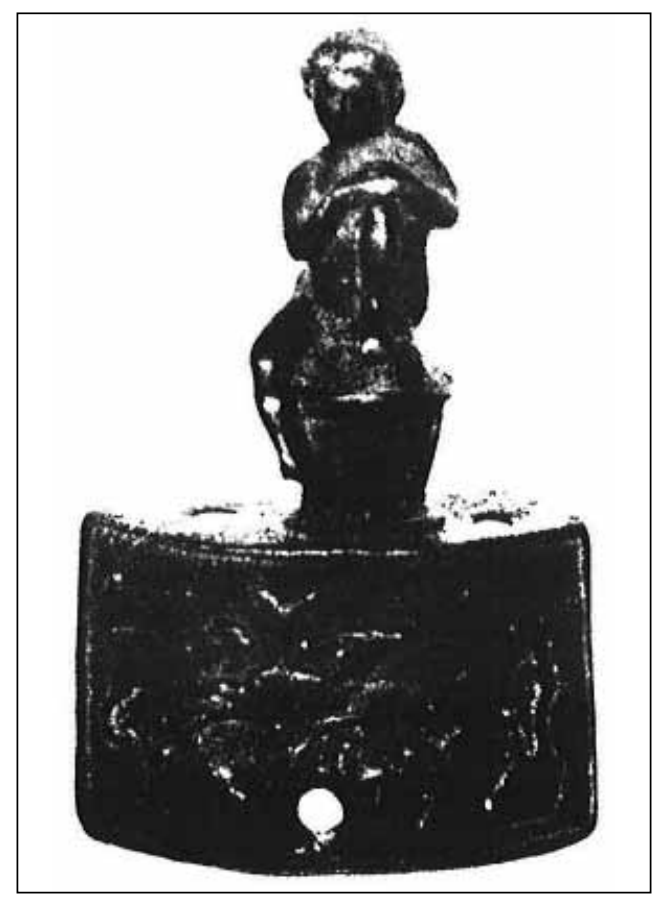

Figura I2. Posible Minerva y pieza de bronce con escena venatoria, de la colección Soto Cortes, hoy desaparecidas, y que pudieron proceder del Ferrán (Diego Santos 1978, 50). La revisión geológica que hemos realizado de este yacimiento, nos permite descartar que estemos ante una mina, como tradicionalmente se había planteado, apostando por un espacio cultual, bien vinculado a la vía de paso que hay junto a la cueva, o bien como espacio funerario. 

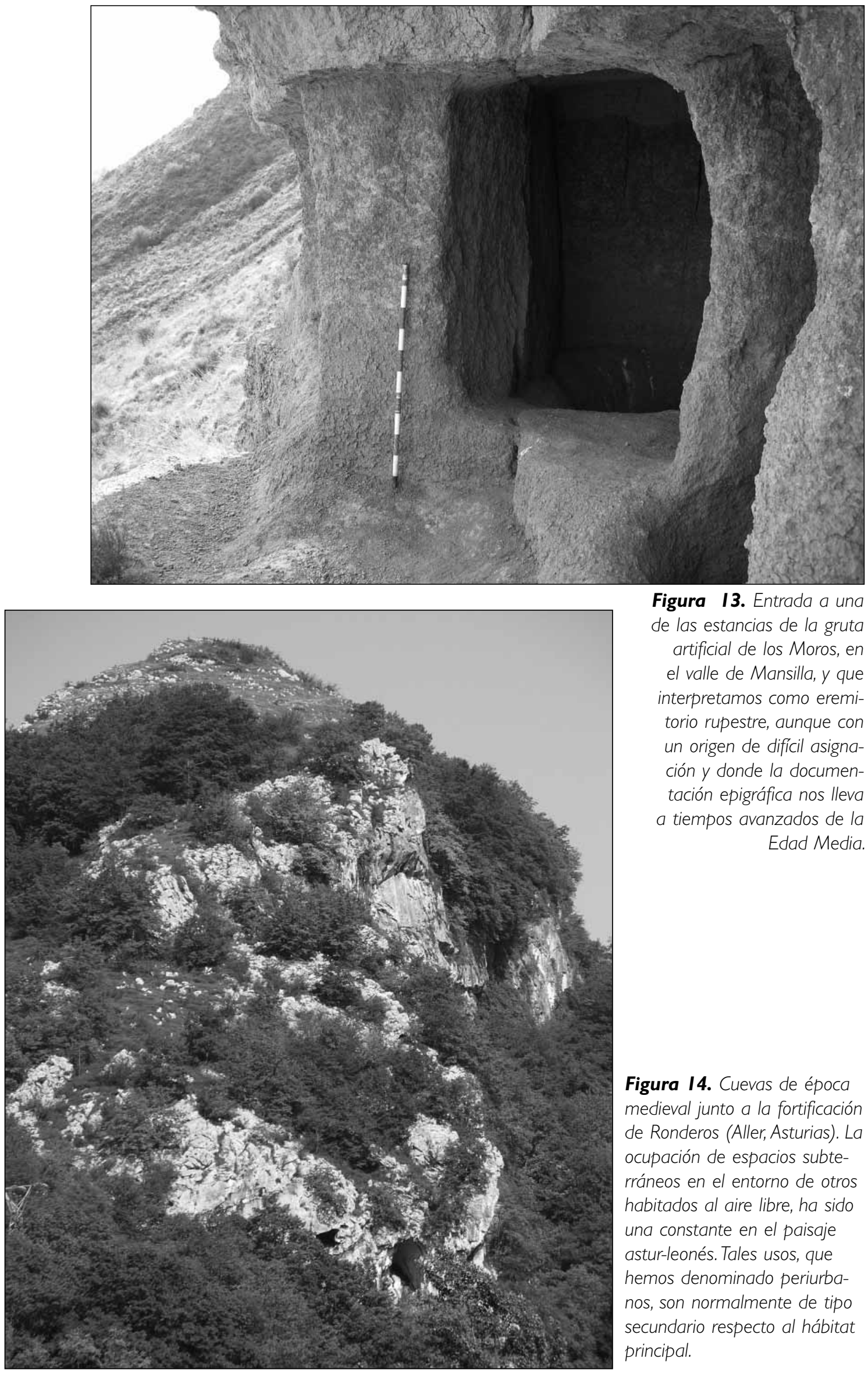

Figura I3. Entrada a una de las estancias de la gruta artificial de los Moros, en el valle de Mansilla, y que interpretamos como eremitorio rupestre, aunque con un origen de difícil asignación y donde la documentación epigráfica nos lleva a tiempos avanzados de la Edad Media.

Figura I4. Cuevas de época medieval junto a la fortificación de Ronderos (Aller, Asturias). La ocupación de espacios subterráneos en el entorno de otros habitados al aire libre, ha sido una constante en el paisaje astur-leonés. Tales usos, que hemos denominado periurbanos, son normalmente de tipo secundario respecto al hábitat principal. 


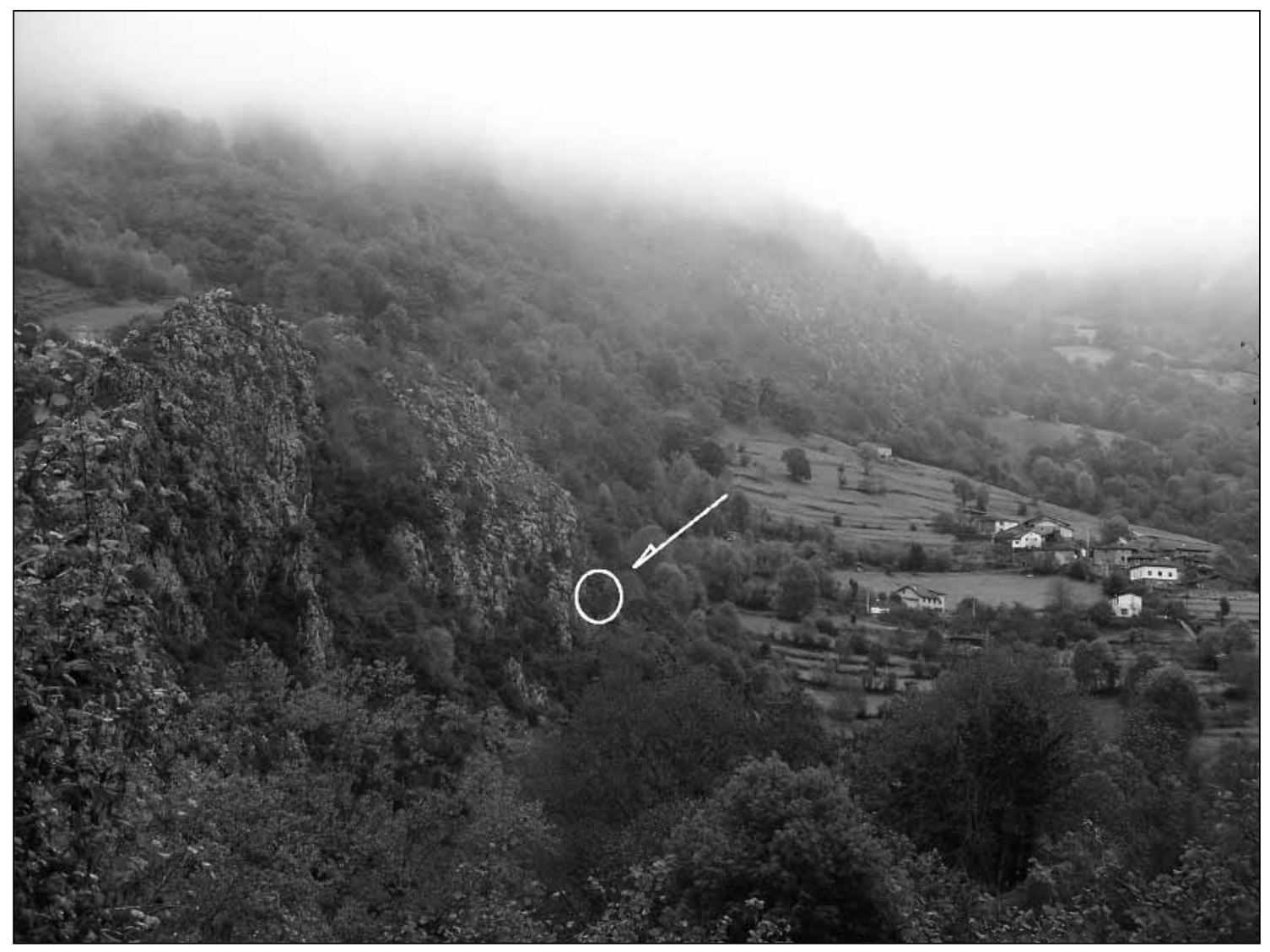

Figura I5. Ubicación de la cueva de Les Beleñes en Ponga (Asturias). La ocupación medieval de espacios de montaña a través de las cuevas, nos lleva a plantear la hipótesis de que algunos de estos emplazamientos subterráneos, pudieran ser el origen de un poblamiento al aire libre posterior, sobre todo, en aquellos lugares donde se permite una explotación mixta del entorno. La constatación futura de esta hipótesis, nos haría plantear la red de cuevas, no como un poblamiento periférico, sino como la base histórica de algunas aldeas de montaña. 